\title{
Anger and its consequences for judgment and behavior: Recent developments in social and political psychology
}

\author{
Alan J. Lambert ${ }^{a, *}$, Fade R. Eadeh ${ }^{b}$, Emily J. Hanson ${ }^{a}$ \\ ${ }^{a}$ Washington University, St. Louis, MO, United States \\ ${ }^{b}$ Emory University, Atlanta, GA, United States \\ *Corresponding author: e-mail address: alambert@wustl.edu
}

\section{Contents}

1. Introduction 105

2. An initial note about terminology 106

3. Part I: On the measurement of anger 107

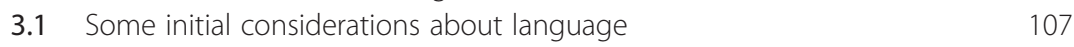

$\begin{array}{ll}3.2 & \text { Lumping vs. splitting } \\ 3.3 & 109\end{array}$

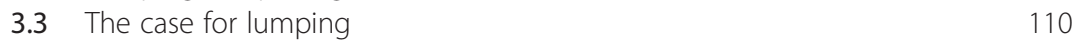

3.4 The "independence" critique 111

3.5 On the misuse of broad-band affective indices in experimental research 112

3.6 Other reasons for splitting anger from other negative emotions 114

4. Part II: The downsides_and upsides_of anger as a social emotion 115

4.1 Anger as an adaptive and socially desirable emotion 116

4.2 Anger and the dynamics of perceived justice 117

4.3 Relevant insights from the social neuroscience area 117

5. Part III: The "functional perspective" and its relation to anger 118

5.1 Extensions of Frijda's work 119

5.2 Does the "function" of an emotion depend on context? 119

5.3 Does context matter in terms of how emotions are immediately
experienced and processed by the individual?

5.4 Does context matter in considering downstream consequences for judgment and behavior? $\quad 120$

6. Part IV: Revenge and the dynamics of anger 123

6.1 On the perceived vs. actual consequences of taking revenge 124

6.2 Perceptual biases in tracking very recent changes in anger 126

note: pre-publication
version; subject to minor
revisions.

Advances in Experimental Social Psychology, Volume 59 
6.3 Our initial research into the revenge killing of Osama bin Laden 127

6.4 On the bittersweet consequences of revenge 130

7. Part V: On the nature of affordances 135

7.1 Threats represent problems that need fixing 135

7.2 Perceived affordances in politics 136

7.3 Hawkishness as a perceived affordance in the fight against terrorism 136

7.4 Implications for anger 137

8. Part VI: Threat, anger, and political attitudes 137

8.1 Experimental studies of the impact of the $9 / 11$ attacks on political attitudes

8.2 Are the political effects of anger consistent for all types of threat? 152

8.3 Further evidence for context specificity: Anger-driven shifts to the political left

9. Part VII: On the relation of our affordance model to extant models of threat 156

9.1 What kinds of threat are being considered? 157

9.2 Are threat-driven ideological shifts relatively broad or narrow? 157

9.3 What is the role of affect/emotion? 158

9.4 On the gap between theory and method 159

10. Part VIII: Anger vs. disgust: How and when are they distinct? 160

10.1 Two illustrative findings from our own work 161

10.2 CODA 163

References 164

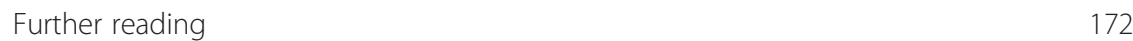

\section{Abstract}

In the eyes of the public - and in a substantial amount of scholarly research - anger is often framed in a negative light, given its role in driving people to act in antisocial ways. However, anger also has the potential for social good, insofar as it focuses attention on, and motivates people to fix, perceived injustices. As we discuss, the foundational link between anger and a desire to rectify injustice has profoundly important implications that are relevant to research and theory in a variety of different disciplines (e.g., experimental social psychology, neuroscience, political science, personality). We begin this chapter by considering the methodological and theoretical challenges involved in the measurement of this feeling state, along with its relevance to our line of research on revenge, as well as the ideological consequences of threat. In the course of this discussion, we introduce a neo-Gibsonian framework of threat which allows for the fact that different types of threats, via anger, can exert different types of ideological consequences. A key prediction of this model-one that distinguishes it from current models of threat-is that activation of anger following threat has the potential to shift political attitudes to the "right" or to the "left," depending on the nature of the threat at hand. These and other findings provide a more comprehensive understanding of this emotion, its relation to (perceived and actual) injustice, and its role in shaping relevant political beliefs. 


\section{Introduction}

Dating at least as far back as Darwin (1872), scientists have acknowledged the evolutionary origins and benefits of positive and negative emotional experience. When the discussion turns to the latter, many scholars cite the adaptive value of pain and fear, such as that offered in this elegant passage by Nesse and Williams (1996):

We need our pains and our fear. They are normal defenses that warn us of danger. Pain is the signal that tissue is being damaged... [and] fear is a signal that a situation may be dangerous, that some kind of loss or damage is likely, and that escape is desirable. Pain and fear, the sources of so much human suffering, the targets of much medical intervention, are not themselves diseases or impairments but instead are normal components of the body's defense.

pp. 67-68

Nesse and Williams (1996) did not consider anger in their essay but could easily have done so. Anger, too, can be highly adaptive. Evolutionary theorists usually frame this point in terms of the adaptive value of aggressive behavior, with the caveat that aggression aids survival when used strategically (e.g., Brown, 1964; Daly \& Wilson, 1988; Smith, 1974). However, many points made about aggression (the overt act) can also be made about anger (the internal feeling).

In particular, we need anger, just as we need fear and pain. Anger is the feeling that warns us that something unjust has occurred. It is a signal that something about the self, or ingroup, could be (or has been) harmed, and that a response to the offending party is needed. As in the case of fear and pain, anger is often maligned as something that is "bad," in the sense that it should be controlled or even gotten rid of. As we discuss later, anger obviously has the potential to trigger undesirable consequences and there are many contexts in which this emotion should be controlled. However, anger-like pain and fear-serves a vital role, and it would be difficult to imagine life without it.

It would be foolish to presume one chapter-or even an entire bookcould fully account for the antecedents and consequences of anger. We do not attempt to do so here. Instead, we focus our attention on topics of longstanding interest to experimental social psychology, including the dynamics of justice and perceived threat. Along the way, we shall cite and discuss relevant work by scholars in related but distinct fields, such as political 
psychology, social neuroscience, personality, and social anthropology. In the context of this discussion, we consider some interesting - and, in some cases, counter-intuitive - things we have learned about anger. Equally important, we also consider aspects of anger about which we have not yet learned, in the interest of stimulating further work on this fascinating and complex emotion.

After a brief note about terminology, we open with a consideration of measurement, a topic with important ramifications for the research to be considered later. We then follow with a discussion of the societal "downsides" vs. "upsides" of anger, with the latter emphasizing its adaptive value in many domains, including the dynamics of justice. The remainder of our chapter concerns the consequences of anger for social attitudes behavior in the context of threat, with emphasis on its ramifications for political opinion.

In a latter part of this chapter, we propose an Affordance Model of threat, which offers a theoretical perspective on anger - and threat more generallywhich, in some ways, contrasts sharply with existing formulations in the social psychological literature. As we will show, a major prediction of our model is that the ideological consequences of threat depend on what type of threat one is considering. For certain types of threat, the activation of threat-driven anger can increase the perceived positivity of certain aspects of conservatism, but other types of threat can increase the appeal of liberalism (Eadeh \& Chang, in press; Eadeh et al., 2018; see also Lambert et al., 2010). In these and other ways, a story about anger is an interesting one. Let's begin.

\section{An initial note about terminology}

Nearly all scholarly work on affect begins with a note on terminology. We shall do the same. In many cases, affective reactions represent a response to a specific stimulus. These are emotions. The emotion-eliciting stimulus may be concrete (e.g., a picture of a spider, your cousin Bob) or more abstract (e.g., "What kind of feelings do you associate with socialism?"). Either way, emotions are "elicited $b y$ something, are reactions to something, and are generally about something" (Ekkekakis, 2013, p. 322; see also Russell, 2003; Russell \& Barrett, 1999). People can also have affective experiences less directly connected to a concrete stimulus (e.g., "I'm feeling happy today"). Such experiences are typically categorized as moods, which "lack a clear referent, may come about gradually, may last for an extended time, and are often of low intensity" (Schwarz \& Clore, 2007, p. 386).

The distinction between emotion and mood is best regarded as fuzzy rather than razor-sharp. For example, many social psychologists (including us) 
use mood inventories to track affective reactions following an experimental manipulation. This might involve, say, having all participants complete the same mood inventory, after having been randomly assigned to read a story about a terrorist attack vs. an affectively neutral control condition. Technically speaking, this approach is measuring mood, because the instructions do not refer to a given stimulus (e.g., "for each of the following adjectives, please tell us how you feel right now"). However, one could argue that participants may infer (implicitly, if not explicitly) that this task is being used to track their affective reactions to the story they just read. We shall return to this issue in more detail later in this chapter.

\section{Part I: On the measurement of anger}

In writing this chapter, our overriding goal was to summarize and synthesize our understanding of anger, especially in the context of models conceptualized in the social and political psychology literature. As such, a focus on methodological issues - how researchers measure anger - might seem tangential to this aim. However, method and theory cannot be separated in any meaningful way. Indeed, as one of the authors noted in a different (but still relevant) context, "method can influence, as well as be influenced by, the process in which researchers develop, test, and refine their theoretical formulations" (Lambert \& Scherer, 2013, p. 33). The intersection of method and theory is particularly relevant when one considers the ways scientists operationalize anger vis a vis other types of negative affect, as we shall show.

\subsection{Some initial considerations about language}

The vast majority of research on affect relies - in one way or another-on the overt expression of inner states. This includes self-report measures using Likert-type scale (e.g., please rate how angry you feel along a scale ranging from 1 to 7) with all of its well-known advantages (e.g., ease of use) and disadvantages (e.g., report biases). Overt expressions of affect can also be studied in more "unstructured" contexts, such as analyzing the content of spontaneously-generated language in response to other people and events (Pennebaker, Booth, Boyd, \& Francis, 2015; see also Abe, 2011; Kahn, Tobin, Massey, \& Anderson, 2007). We have used this approach in our own work, in the context of studying the affective consequences of revenge (Eadeh, Peak, \& Lambert, 2017), and the affective dynamics relevant to research in the terror management area (Lambert, Eadeh, et al., 2014). These techniques avoid some issues associated with traditional self-report 
indices. Yet, they still rely on language (albeit in a more subtle, nonintrusive manner), and this brings us back to our original point: human language serves many important functions, and one of these is to convey how we feel to others.

Over the last few decades, researchers have developed sophisticated techniques that eschew the measurement of language altogether, including videotaping/photographing facial expressions (Ekman \& Rosenberg, 1997), tracking relevant changes in heartrate (Ekman, Levenson, \& Friesen, 1983), and assessing changes in cortical activity (for an overview, see Beer, 2017). These developments have enriched our understanding of emotional experience, including anger. As discussed ahead, research and theory in social neuroscience has done much to tell us how and why this emotion is different from other negative emotions and similar to positive feelings (Carver \& Harmon-Jones, 2009).

As valuable as these new techniques are, we are inclined to agree with Russell and Carroll (1999), who predicted that self-report will remain the primary - although certainly not the only — way of operationalizing the phenomenological experience of emotion. We emphasize the phrase "experienced" because many measurement tools (e.g., fMRI technologies) track aspects of human emotion that are either partially or wholly outside of our awareness. To reiterate, these recently developed tools are immensely valuable and have added much to our understanding of how emotions guide our processing of information. However, this approach does not measure emotional experience, at least as that term is typically used.

These considerations highlight an important distinction noted by LeDoux (1994). On the one hand, elements of emotion-related processing can certainly lie outside of awareness (e.g., Berridge, 2003; LeDoux, 1996; Winkielman, Zajonc, \& Schwarz, 1997). However, emotional experiences themselves are, by definition, part of conscious experience. Or, as Clore (1994) states, "it is not possible to have an unconscious emotion because emotion involves an experience, and one cannot have an experience that is not experienced" (p. 285). A careful reading of Clore (1994) reveals that he was not dismissive of the importance of studying nonconscious aspects of emotional processing. Rather, he asserted the importance of consciousness when researchers are interested in studying how people use their experience of emotion as a basis for judgment or behavior. This is our position as well. In summary, the study of anger-as with any other affective state - can involve a variety of methodological tools. Some tools focus on affective experience, whereas other tools focus on the underlying 
processes associated with such feelings. In combination, each of these approaches offers a different but complementary perspective as it applies to our theoretical understanding of emotional experience, including anger.

\subsection{Lumping vs. splitting}

Scientists often face an interesting dilemma: When measuring phenomena of interest, is it better to use broad-band measures and classification systems (lump) or to make fine-grain distinctions (split)? The origin of these terms is attributed to Charles Darwin who, in a letter to J.D. Hooker, wrote “Those who make many species are the 'splitters,' and those who make few are the 'lumpers."' Although the lumper-splitter debate seems to have originated in biological classifications, it represents an important issue in psychology. For example, there have been long-standing debates about the value of constructing broad vs. fine-grained classification in the realm of intelligence (Gardner, 1983; Neisser et al., 1996; Spearman, 1904) and personality (Allport, 1937; Cattell, 1957; Costa \& McCrae, 1985, 1995; Eysenck, 1952).

This debate is also relevant to questions about the way we study emotion, including anger. More specifically, should anger be operationalized in a way that highlights its distinction from other types of negative affect (e.g., fear, sadness, guilt)? Intuition suggests we should. For one thing, the phenomenological experience of anger-how it feels-seems different from other emotions. It is hard to imagine someone being confused, for example, as to whether they are feeling angry or shameful. Moreover, the events that cause us to feel anger are often different from the events that lead us to experience other types of negative emotions. As noted ahead, intuitions about the value of making such distinctions are bolstered by empirical research, such as work showing that the neurological processes associated with anger are different from other negative emotions. These are the types of points that splitters like to make. As the reader might have guessed by now, we are unabashed splitters.

However, the splitter approach has not been universally embraced. Indeed, the lumper approach to affect is far more dominant in certain areas of experimental social psychology. Here we refer to the widespread practice of forming "broad band" indices of negative affect that lumps anger with other facets of negative affect, such as anxiety, guilt, and shame. In fairness to our lumper colleagues, there is some justification in forming broad categories of emotion (at least in certain contexts), as we discuss ahead. 
As we shall point out, however, we believe social psychologists have arguably extended this practice to inappropriate contexts (for a related discussion, see Harmon-Jones, Bastian, \& Harmon-Jones, 2016).

\subsection{The case for lumping}

In this context, "lumping" refers to the practice of forming indices that average across correlated emotional states sharing the same valence. The most well-known example of this approach is the classification scheme proposed by Watson and his colleagues. In a widely-cited article, Watson, Clark, and Tellegen (1988) suggested that affect should be conceptualized in terms of two independent factors - Positive Affect (PA) and Negative Affect (NA) and these "represent the major dimensions of emotional experience" (Watson \& Tellegen, 1985, p. 34). The PA index averages across 10 positive items (attentive, interested, alert, enthusiastic, excited inspired, proud, determined, strong, and active), and the NA index averages across 10 negative items (afraid, scared, nervous, jittery, irritable, hostile, guilty, ashamed, upset, and distressed). As seen by their content, the PA and NA indices collapse across emotional states that most laypeople would regard as distinct. For example, the NA index includes two anger-related items (hostile, irritable), but these are combined with items measuring guilt, shame, and anxiety. ${ }^{a}$

The approach advocated by Watson and his colleagues has been extremely influential (see Huddy, Feldman, \& Cassese, 2007). As one marker of its impact, the paper that introduced the PANAS - Watson et al. (1988) has over 30,000 citations (per Google Scholar) and is second only to Baron and Kenny (1986) for articles appearing in the Journal of Personality and Social Psychology, widely regarded as the flagship journal of social psychology. As we shall show, Watson's framework has also elicited strong criticism,

\footnotetext{
a A subsequent modification (the PANAS-X; Watson \& Clark, 1994) expanded the number of items in the mood inventory from 20 to 60. Watson and Clark (1994) appeared to relax their focus on the PA and NA indices, providing guidelines for the formation of more emotion-specific subscales. However, even with this expansion, the vast majority of studies have continued to rely on the original 10-item PA and NA indices (Harmon-Jones et al., 2016; see also Lambert et al., 2014). One possible reason for this trend is that use of the PA/NA indices was already ubiquitous by the time the PANAS-X was published. As Harmon-Jones et al. (2016) have noted, researchers tend to gravitate towards well-validated measures, especially when they are already popular. In any event, we make note of these considerations, because there is nothing in the PANAS/PANAS-X per se that prevents researchers from forming more emotion-specific indices of affect. The choice to "lump" arises afterwards, in the context of forming composites to be used for statistical analysis.
} 
and not all researchers employ the PANAS approach. Nevertheless, this easily represents one of the most widely-used techniques to operationalize affective experience.

There are several reasons why this approach has become so popular. For one thing, the two-factor solution proposed by their model is highly replicable and has emerged in many studies across a diversity of research paradigms. The PA and NA indices, noted above, are statistically reliable and are meaningfully correlated with a wide range of outcome variables (for a review, see Tellegen, Watson, \& Clark, 1999). Also, many dedicated splitters (like us) are compelled to acknowledge that affective states sharing the same valence are strongly correlated with each other.

In our own work on terrorist threat, for example, we typically form separate composites of anger and fear when measuring affective reactions to reminders of a specific terrorist act (e.g., the 9/11 attacks). In these studies, we often find substantial correlations between these indices, ranging between 0.40 and 0.60 . Even acknowledging the problem of common method variance (which has the potential to inflate such correlations; Nunnally, 1978), there is no doubt that anger and fear are strongly related. These kinds of relationships are not the onl $y$ justification for taking a lumper approach. But the strong overlap between distinct types of negative affect is often striking and is one reason why the formation of broad-band indices of affective experience can make sense in many-but not all-contexts.

\subsection{The "independence" critique}

Some problematic aspects of Watson's model can, and have been, raised. The most commonly-voiced objection, by far, has centered on the independence assumption (Russell \& Carroll, 1999). Here we refer not only to the independence of the PA and NA indices themselves, but also, more broadly, to the presumption that positive and negative emotional experiences are orthogonal to each other. Although there is some evidence that these experiences are independent of each other (Tellegen et al., 1999; Watson et al., 1988; see also Goldstein \& Strube, 1994), other researchers have argued that this independence is a statistical artifact, reflecting what critics regard as illadvised choices in the conceptualization and operationalization of the PA and NA indices. The details of this critique, though extremely important, involve complex issues concerning factor analytic techniques as well as the modeling of measurement error, both of which are beyond the scope of this chapter (for further discussions, see Crawford \& Henry, 2004; Green, Salovey, \& Truax, 1999; Russell \& Carroll, 1999). 


\subsection{On the misuse of broad-band affective indices in experimental research}

Setting aside debates over the independence assumption, there is another shortcoming of using the PA and NA indices: they are often used in contexts for which they were never intended. This problem does not pertain to the theoretical model developed by Watson and his colleagues per se. Instead, the problem is with the way these indices have been used by other researchers (especially, social psychologists). To understand this problem, it is useful to elaborate on the research goals that originally led to the development of the PANAS.

By and large, the PANAS was initially developed with the purpose of capturing relatively stable aspects of human emotional experience, to be used as a basis for predicting variables of interest to clinicians (e.g., depression, anxiety) and personality researchers (e.g., agreeableness, neuroticism). In other words, the PANAS was intended to be used as a marker of individual differences. Although the PANAS has its share of psychometric challenges to the independence assumption (see above), the PANAS has been very useful when used in this manner (Tellegen et al., 1999; Watson \& Clark, 1992; Watson et al., 1988).

Experimental social psychologists often have different goals in mind when measuring affective experience. Instead of assessing individual differences, they are often interested in assessing context-specific reactions to a given experimental manipulation. This would include, for example, assessing participants' affective experiences after being assigned to a threat vs. non-threat condition. Hundreds of studies in the social psychological literature have used the PANAS for this purpose. However, the PANAS was never designed to be used in this manner. Moreover, this unfortunate trend has led to some demonstrably incorrect conclusions. In the discussion to follow, we make note of these problems, drawing from our own work (Lambert, Eadeh, et al., 2014; Lambert, Peak, et al., 2014; Lambert et al., 2010) along with related points made by Harmon-Jones et al. (2016).

\subsubsection{Emotion-specific manipulations warrant emotion-specific measures}

Most experimental research uses inductions developed with a specific purpose in mind. If you were interested in how people cope with the awareness of their own mortality, for example, you would want to use a task that makes those concerns salient. If you were interested in inducing uncertainty, you would want a manipulation that induces uncertainty. These are only two 
examples of a much larger point: experimental manipulations tend to be rather specific in terms of what kinds of psychological constructs they are designed to activate. Most relevant to present concerns, they are likely to trigger specific types of affective experiences.

These points may seem obvious in retrospect. However, some important areas of research within experimental social psychology use broad-band measures of affect (such as the PA and NA indices) immediately after using a specific type of manipulation that is likely to trigger a specific type of affective reaction. For example, among the hundreds of studies in the terror management literature, nearly all of these use a mortality salience (MS) induction, which is far more relevant to feelings of fear/terror compared to (say) shame or embarrassment. However, nearly all of these investigations use the PA and NA indices to assess the affective impact of MS. In a similar vein, research on uncertainty management theory (UMT; Van den Bos \& Lind, 2002; Van den Bos \& Miedema, 2000; Van den Bos, Poortvliet, Maas, Miedema, \& Van den Ham, 2005) uses manipulations that elicit feelings of anxiety and uncertainty. Here, too, researchers frequently rely on the PANAS.

Use of broad-band measures following domain-specific inductions can produce three related problems (Lambert, Eadeh, et al., 2014; Lambert, Peak, et al., 2014; Lambert et al., 2010). First, the insensitivity of such measures may lead researchers to mistakenly conclude that their manipulation has no impact on affect at all. For example, higher levels of fear in the experimental (vs. control) are likely to go undetected if researchers employ the NA index, given that this measures a wide range of different emotions which may be wholly unrelated to a given manipulation. Second, such spurious conclusions make it unlikely that researchers test for affective mediation, even though such mediation may, in fact, be detectable using more sensitive measures. Third - and most broadly-mistaken conclusions about the minimal role of affect may lead to the misguided conclusion that one's findings are not relevant to important research in the emotion literature. For example, if a researcher erroneously concludes that his or her manipulation has no impact on any type of negative affect, this would decrease the chance of forging potentially important theoretical connections with models of social judgment and mood (Forgas, 1995; Lerner, Li, Valdesolo, \& Kassam, 2015; Schwarz, 2012; Västfjäll et al., 2016).

Our own work has highlighted all three consequences in the context of the terror management and uncertainty management paradigms (Lambert, Eadeh, et al., 2014; Lambert, Peak, et al., 2014; Lambert et al., 2010; 
see also Eadeh et al., 2018). In particular, researchers in these areas have long claimed that their manipulations produce no measurable changes in overt emotional experience. However, when affect-specific indices of negative emotion are used (i.e., especially pertaining to fear), one regularly observes statistically significant and large (in terms of effect sizes) effects when compared to a neutral control condition. Moreover, mediational analyses show the activation of these feelings has important downstream impact on constructs of long-standing interest to these researchers (e.g., self-esteem) and which are relevant to extant theories of emotion and mood (Forgas, 1995; Schwarz, 2012).

This line of reasoning does not imply that every finding in the TMT area involves affective mediation. Indeed, Lambert, Eadeh, et al. (2014) and Lambert, Peak, et al. (2014) found the impact of the MS manipulation on patriotic attitudes occurred independent of fear and anxiety. From the standpoint of TMT, this is notable, because one of the predictions of the model is that MS should increase the psychological appeal of relevant ingroups. However, self-esteem is also a critical part of TMT, and we (Lambert, Eadeh, et al., 2014) repeatedly found that fear and anxiety did mediate changes following the MS prompt. Our larger point is that MS reliably triggers large changes in affective experience and, for this reason alone, it is important to empirically test when such affect is responsible for MS-driven changes and when it is not. ${ }^{\mathrm{b}}$

\subsection{Other reasons for splitting anger from other negative emotions}

As we have discussed, one reason for avoiding the PA and NA indices is the problem of measurement insensitivity, especially when these indices are employed as state-based measures of affect. Beyond this general issue, there is research showing that different types of affective experience can have markedly different consequences for action and thought, even if they share the same valence and are significantly correlated (Frijda, 1986; Lerner \& Keltner, 2000; Lerner et al., 2015; Schwarz, 1990, 2012; see also Huddy et al., 2007).

\footnotetext{
${ }^{b}$ We have focused our attention here on TMT and UMT because these are the areas of research most germane to our own work. However, the problem of using broad-band measures following specific experimental manipulations is also relevant to other areas of research. For example, studies in the social exclusion area rarely use measures of affective experience that are specific to the feelings of social exclusion. This provides one (but perhaps not the only) explanation for why studies in this area frequently report null/weak effects of their manipulations on affective experience (see also Blackhart, Nelson, Knowles, \& Baumeister, 2009).
} 
A major theme of this work is that different emotions serve different functions (i.e., goals), and this often justifies the formation of more emotion-specific measures. (For an excellent review, see Lerner et al., 2015.)

Research and theory on anger provides some of the most compelling rationale for taking an emotion-specific approach. On the one hand, anger is obviously a negative emotion and correlates with other types of negative feelings (e.g., fear, sadness). Yet, unlike other negative emotions, anger is part of the approach system (Carver \& Harmon-Jones, 2009; Harmon-Jones, HarmonJones, Abramson, \& Peterson, 2009; Harmon-Jones, Price, Gable, \& Peterson, 2014). Hence, contrary to intuition, anger shares some important qualities with other positive emotions, like joy or happiness. Relevant, too, are data showing (a) the impact of anger on information processing is distinct from other negative emotions (Bodenhausen, Sheppard, \& Kramer, 1994; Keltner, Locke, \& Aurain, 1993), as well as (b) the unique role of anger in justice-related dynamics. We discuss these matters in more detail ahead.

\section{Part II: The downsides-and upsides-of anger as a social emotion}

Most people intuitively regard anger as a deeply unpleasant feeling that should be managed and controlled. Or, better yet, not to be experienced at all. One of the more famous indictments of anger was offered by the Greek philosopher Seneca, who regarded anger as a "hideous and wild" emotion, one that is a "short madness....raging with an utterly inhuman lust for arms, blood and tortures, careless of itself provides it hurts another, rushing upon the very point of the sword, and greedy for revenge even when it drags the avenger to ruin with itself."

It is easy to understand why anger has such a bad reputation. As Seneca suggests - and as psychological research confirms - anger has the potential to trigger a vast array of socially undesirable behaviors, most notably in the context of driving many criminally aggressive acts, such as assault or murder (Anderson, 2001). Although anger has no separate entry in the most recent version of the DSM, there are at least 30 diagnosable illnesses (e.g., intermittent explosive disorder) in which anger or related sensations (e.g., irritability) are listed as a diagnosable problem. Higher levels of anger or hostility are also predictive of negative health outcomes for the self, including higher risk for cardiovascular disease (Bond \& Wingrove, 2010; Dutton, 2010; Stemmler, 2010). 
In addition to its obvious liabilities for personal interactions, anger can goad human beings to commit truly horrific acts on a more collective level, in the context of atrocities of genocide and most wars (Mishra, 2017). It would take many additional pages to even summarize the plethora of social ills (individual and collective) attributed to anger. The fact that we do not do so obviously has nothing to do with our desire to excuse or exonerate this emotion. Rather, we defer this kind of discussion mostly because the downsides of anger are so well known and so often written about. Less often considered are the advantages of anger, an issue we turn to next.

\subsection{Anger as an adaptive and socially desirable emotion}

As counterintuitive as this may seem, anger also has some strong upsides. This perspective is clear from the writings of Aristotle, who (unlike Seneca) promoted the virtues of anger, citing its value when "felt towards people who are not justified in slighting us." Aristotle was careful to note the appropriate use of anger is key in this consideration: "Anybody can become angry - that is easy, but to be angry with the right person and to the right degree and at the right time and for the right purpose, and in the right way - that is not within everybody's power and is not easy." Even taking this caveat into consideration, the Aristotelian perspective is important, as it foreshadows conclusions reached by researchers over the last two centuries.

For example, Darwin (1872) suggested that the experience and expression of emotion-including anger-prepare an organism for action and facilitates communication to others (see also Hess \& Thibault, 2009). Anger can also play an adaptive role in promoting success in mating and resource protection against intruders (Tooby \& Cosmides, 1992). A related line of evolutionarily-themed work has illustrated the role of anger in promoting harmony within groups. Cooperation among ingroup members depends critically on limiting "free riders" (i.e., those who take more than their fair share of valuable resources). The activation and public expression of anger upon noticing an infraction (a) helps maintain one's attentional focus on that event, (b) motives punitive aggression toward the offender in question, and (c) serves as a "warning signal" to others contemplating such acts in the future (Fehr \& Gächter, 2002; see also Axelrod \& Hamilton, 1981; Hopfensitz \& Reuben, 2009; Seip, Van Dijk, \& Rotteveel, 2014). 


\subsection{Anger and the dynamics of perceived justice}

One of the larger implications of the preceding discussion is that anger is triggered by a perception that the world is "not right"; that something has happened that should not have happened. Once activated, anger motivates people to re-establish a sense of justice. In the following discussion, we shall discuss in some detail the reasons why anger is so central to these considerations. Before doing so, it is important to acknowledge the subjectivity of this process: The extent to which any given event is perceived as unjust is determined by the perceiver, and contingent on his or her own vested interests (e.g., group membership, attitudes, ideology). For example, a group of people hailed as freedom fighters from one perspective are often framed as terrorists in another. More generally, human beings have a remarkable ability to rationalize acts of violence as "good," even when others see the same act as unambiguously bad.

Another subjective element comes into play in terms of how, exactly, people elect to rectify justice. As researchers in the justice area have long recognized, there are many routes by which people can "make things right." Some routes potentially involve aggression and violence (e.g., in the form of retributive justice), whereas other routes may involve more peaceful strategies, such as in the case of restorative justice. The different routes by which people seek to restore justice is an important area of research in its own right (for relevant discussions, see Bobocel, Kay, Zanna, \& Olson, 2011; Callan, Sutton, Harvey, \& Dawtry, 2014; Hafer \& Olson, 2003). For present purposes, our main point is that anger serves as a critically important motivator to do something about it. ${ }^{c}$

\subsection{Relevant insights from the social neuroscience area}

The role of anger as a motivational agent fits nicely with the finding that anger is apparently unique among negative emotions in terms of its importance to the behavioral approach system. More specifically, studies have

\footnotetext{
As a reader of an early draft of this chapter noted, the upsides and downsides of anger, at least as it pertains to the justice motive, could be framed as different sides of the same coin. When we perceive an injustice in the world, anger motivates us to do something about it. When others agree with this assessment, and approve of the measures we take, anger is good. However, when we see injustice whereas others do not, and/or we act in ways that are perceived as trampling the rights of others, anger is bad. As with all relativist positions this line of reasoning can go too far. There are some events (e.g., death of an innocent child) that nearly everyone can agree is wrong. However, our own view of these matters is that many everyday examples of perceived injustice involve a substantial amount of subjectivity.
} 
shown that the activation of anger is associated with increased left frontal activity and decreased right frontal activity (Harmon-Jones \& Allen, 1998; Harmon-Jones, Gable, \& Peterson, 2010), a pattern which provides a reliable neurological "signature" of approach (vs. avoidance). Evidence for this idea has been generated in the context of studies focusing on trait-based (i.e., chronic) experiences of anger as well as experimental inductions (Carver \& Harmon-Jones, 2009). Converging evidence has been shown in studies that experimentally manipulate brain activity (e.g., via transcranial magnetic stimulation): manipulations that ultimately stimulate the approach centers of the brain (i.e., the left frontal cortex) induce selective attention toward angry faces, whereas experimentally-induced activation of brain areas associated with avoidance (i.e., the right frontal cortex) produces the opposite effect (Hortensius, Schutter, \& Harmon-Jones, 2011).

The alignment of anger to approach motivation has several far-reaching implications. We have already noted the implications of such findings for the way anger is conceptualized and operationalized relative to other negative feelings, as well as its role in motivating people to "fix" perceived injustices. As we discuss ahead, these matters have more specific implications for understanding the affective antecedents and consequences of revenge, as well as changes in attitudinal preference following the activation of threat.

\section{Part III: The "functional perspective" and its relation to anger}

One of the rationales for taking an emotion-specific approach to measurement and theory is that different emotions are relevant to different types of psychological functions and goals. This perspective owes much to the seminal work of the Dutch psychologist Nico Frijda (1986, 1988). Frijda believed emotions serve as a "signaling" device that highlights an important concern (i.e., need-state, goal) of the organism and propels the organism to do something about it. Frijda was clearly focused on the role of emotion in motivating overt behavior, a process he labeled as "action tendencies."

In Frijda's view, all these elements of emotion - their role as signals, the needs with which they are associated, and their action tendencies-are meaningfully different for different types of emotions:

The emotion we call fear signals a threat to the concern that is involved in the emotion-eliciting event: one's physical integrity, one's prospect of success, the stability of one's intimate relationship with a particular individual... and so forth. The emotion called anger signals (among other things) actual or impending offense to 
such a concern. Joy signals that an event means achievement of satisfaction with regard to a given concern or a promise that such achievements are within reach.

Frijda and Mesquita (1994, p. 54)

Consistent with this general perspective, Frijda and Mesquita (1994) discussed the different social functions served by distinct emotions, contrasting (among other things) the differences between anger from fear or shame.

\subsection{Extensions of Frijda's work}

In most of his work, Frijda placed emphasis on the social functions of emotions and stressed their "role in shaping people's responses to their social environments and in coordinating interactions between individuals" (Van Kleef, 2017, p. 212). Extensions of Frijda's work maintain this connectivity to interpersonal dynamics but have broadened their scope. One example is the "affect as information" approach by Schwarz and colleagues (Schwarz, 2012; Schwarz \& Clore, 2007). Although this model has generated many insights, one primary message is that different emotions have different consequences on information processing, including the extent to which people engage in controlled vs. automatic processing. For example, sadness triggers controlled processing (Huntsinger, Isbell, \& Clore, 2014; Lambert, Khan, Lickel, \& Fricke, 1997; Raghunathan \& Pham, 1999), but anger can elicit heuristic processing (Bodenhausen et al., 1994; Tiedens \& Linton, 2001).

A similar perspective can also be seen in an important line of work by Lerner and Keltner (2000, 2001; see also Lerner et al., 2015). Among other things, this work shows that anger stimulates optimistic appraisals of the environment and greater tolerance of risk, which is the exact opposite of fear. In addition, anger and fear play different roles in the context of terrorist threat (Lerner, Gonzalez, Small, \& Fischhoff, 2003). For example, anger (but not fear) stimulates aggressive retaliation against the outgroup. However, people's concerns about future terrorist attacks are primarily rooted in fear, not anger.

\subsection{Does the "function" of an emotion depend on context?}

Any given emotion can be elicited in a variety of different contexts. In the specific case of anger, there are a near-infinite number of unjust events that could trigger this emotion. This can include affronts that occur to the self (e.g., being accused of something you didn't do), another individual (e.g., perceptions that someone has been unfairly denied insurance coverage), 
or a group as a whole (e.g., a pre-meditated attack on innocent civilians). The same principle applies to any other emotion. For example, fear is obviously linked to matters of safety threats, but this can arise in a near infinite number of contexts and stimulus triggers (e.g., snakes, public speaking, first dates).

These considerations raise an important issue. Given that any given emotion can be elicited in a diversity of contexts, one needs to consider whether this contextual variation matters. This is an area fraught with disagreement and debate (Johnson \& Tversky, 1983; Wilson-Mendenhall, Barrett, Simmons, \& Barsalou, 2011). However, we believe some of this debate reflects confusion over what we mean by "context." Instead of framing this issue as a broad question (i.e., "Does context matter?"), it is useful to divide this issue into two distinct questions (Eadeh, 2017), which, as shown below, have two different answers.

\subsection{Does context matter in terms of how emotions are immediately experienced and processed by the individual?}

One way of framing these considerations is to ask whether context plays a role in terms of how emotion is immediately experienced and processed. The answer appears to be yes. Indeed, the initial circumstances in which the emotion is elicited can make a difference in terms of the phenomenological nature of the emotion itself (i.e., how it feels to the self), its biological resonances (e.g., how it affects our bodily reactions, such as heartrate), and the pattern of neurological activity in the brain. In an interesting line of research by Wilson-Mendenhall et al. (2011), for example, the neurological responses associated with feelings of anger depended on whether the triggering stimulus was social vs. non-social in nature. Similar contingencies were also found in the case of fear (Wilson-Mendenhall et al., 2011).

\subsection{Does context matter in considering downstream consequences for judgment and behavior?}

A second way of framing the context question is in terms of the downstream consequences of emotion for judgment and behavior. In the field of social psychology, investigators often employ designs in which they initially "prime" a given emotion in the first part of the study (e.g., by having participants read a story, watch a film), with an interest in examining how the activation of this feeling state influences later judgments and behaviors. There is an enormous body of evidence showing that the activation of affect can have profoundly important consequences for a huge number 
of outcome variables (e.g., impressions and attributions we form of others, reliance on automatic vs. controlled processing, assessment of risk; for reviews, see Forgas, 1995; Lerner et al., 2015; Schwarz, 2012).

The more relevant issue at hand is whether the exact circumstances/reasons that led to the elicitation of an emotion make a difference in terms of its subsequent impact on the criterion variable. For example, should anger carry similar downstream consequences for social judgment, independent of the reasons this feeling became activated? According to one view, the circumstances under which emotion was initially activated do not matter. A very well-known line of research reported by Johnson and Tversky (1983) seems to offer support for this perspective. For this reason, it is useful to consider this work in some detail here.

In one of their studies, participants were assigned to one of four different conditions. Three of these involved reading about the death of a fellow college student under different types of circumstances (i.e., leukemia, fire, homicide), with a fourth non-threat condition serving as the control. In all cases, this was then followed by a task which measured perceptions of risk with respect to a wide range of negative events. Analyses revealed what Johnson and Tversky (1983) call a "global" effect of threat on risk perception. Regardless of how participants were primed with threat, this elevated perceived threat across a wide range of domains.

For example, reading about the death of another person due to homicide led to increased perceptions of risk not only with respect to murder, but also to meteorological calamities (e.g., tornados, lightning). Another study showed a similar pattern of elevated risk across a diversity of negative events, regardless of whether the "priming story" pertained to a student that had been assaulted or, alternatively, had just experienced a painful romantic breakup. These findings could be interpreted as providing evidence for a "general mood" model of risk. In other words, triggering any sort of bad mood could conceivably elevate perceptions of risk, independent of the context that initially triggered those negative feelings, and independent of the particular type of feelings that might be activated.

These findings are important, especially when one considers the historical context in which they were published. The growth of interest in risk assessment in the 1970s and early 1980s had been largely dominated by a cognitively-oriented approach (Kahneman, Slovic, \& Tversky, 1982), emphasizing the critical role of cognitive availability in driving judgment. As Johnson and Tversky (1983) acknowledged in their own paper, these considerations initially led them to expect more "local" (i.e., domain 
specific) priming effects in their own work. The global nature of their findings (see above) led them to conclude that affect may play a more important role in information processing than was commonly presumed at the time. This point is important, because Johnson and Tversky (1983) is often cited as an early and influential "push" to consider the role of emotion and affect in what (at the time) was a rather cognitive approach to understanding social information processing (for a related discussion, see Loewenstein, Weber, Hsee, \& Welch, 2001).

For these and other reasons, the reputation of Johnson and Tversky (1983) as a citation classic is justly deserved. However, certain aspects of their methodology limit some conclusions regarding the role of affect. For one thing, their data imply, but do not actually show, evidence for the mediating role of affect in risk perceptions. For example, only one of their studies measured worry/anxiety (as assessed by a single item), and these feelings were not correlated with perceptions of risk. More generally, their work preceded subsequent insights generated by the functional approach to measuring affect, including the importance of measuring different negative emotions (e.g., fear vs. sadness vs. anger) with multi-item, psychometrically sound indices. In a related vein, work by Lerner and Keltner (2001) has shown that eliciting fear leads to higher perceived risk, whereas anger has the opposite effect.

\subsubsection{The question of context, redux}

This brings us back to the second version of our question about context, introduced earlier. Should one expect similar-or different-consequences of a given emotion depending on the circumstances in which that emotion was initially triggered? For the reasons noted above, the risk-centered work conducted by Johnson and Tversky (1983) cannot provide a definitive answer to that question. Somewhat surprisingly, our review of the current and past literature-including but not limited to research on risk assessment-offers no tangible answers to that question. Particularly important for our purposes, we are not aware of any research that has convincingly tested whether the initial context in which a given emotion is activated does-or does not-determine the kinds of consequences that this emotion has on judgment and/or behavior.

For our part, this gap served as a major motivating force in a line of our own research that examined the impact of threat-driven anger on ideological preferences. As we discuss in more detail ahead, one of the intriguing findings of this work is that the consequences of anger are not context free. 
That is, the ways that this emotion influences political attitudes depends on the particular type of threat that led to the activation of anger in the first place (Eadeh \& Chang, in press; Eadeh et al., 2018). We discuss this research in more detail later in this chapter. For now, however, we shall turn our attention to the role of anger in a domain of great practical and theoretical importance: the dynamics of revenge.

\section{Part IV: Revenge and the dynamics of anger}

People are motivated to see the world as just and orderly, a place in which people get what they deserve and deserve what they get (Callan et al., 2014; Hafer \& Rubel, 2015; Lerner, 1980; Ross \& Miller, 2002). In the case of relatively ambiguous events, such motivation can lead people to draw inferences that confirm one's sense that the world is just after all. One well-known example of this principle is the tendency for people to selectively attend to (and/or remember) information that fosters blame of other people when they have suffered misfortunes (e.g., "she deserved what happened to her"; Quigley \& Tedeschi, 1996).

However, life often presents us with relatively unambiguous events that clearly violate the justice principle. This could include relatively mundane events (e.g., someone cutting ahead of us in line) and far more serious events that can affect thousands or even millions of people (e.g., terrorist attacks). However, such events are relevant to the motivation to see the world as just. In particular, justice-based beliefs serve as a motivational "engine," driving us to take action in order to restore justice and put the world back to where it should be.

This metaphor of an engine is useful, as anger represents a powerful fuel, supplying people with the motivational "push" to rectify injustices and to do something about such infractions (Cottrell \& Neuberg, 2005; Litvak, Lerner, Tiedens, \& Shonk, 2010; Skarlicki \& Folger, 1997). To be sure, justice violations can trigger all sorts of negative emotions (e.g., sadness, fear, anxiety), but anger often dominates one's emotional response to justice violations, especially when the violation is severe and the transgressor is clearly identified (Aquino, Tripp, \& Bies, 2001; Bennett \& Earwaker, 1994; Bradfield \& Aquino, 1999; Darby \& Schlenker, 1982; Lickel, Miller, Stenstrom, Denson, \& Schmader, 2006). However, the point is not just that injustice triggers anger. More important for present purposes, anger makes us do something about such violations, a point that fits nicely with aforementioned research highlighting the role of anger as an action-oriented variable. 
Anger serves as a primary motivator for action, even when the particular "justice-restoring" route does not involve overt acts of aggression per se (e.g., in the case of a desire to compensate the victim; Darley \& Pittman, 2003). In other cases, motivations to restore justice can involve overt acts of hostility. One important facet of such aggression is revenge, which has been defined by Osgood (2017) as an "action in response to some perceived wrongdoing by another party intended to inflict damage, injury, discomfort, or punishment on the party judged responsible (p. 1)." As Osgood (2017) notes in his excellent review of the literature, anger-fueled desires for revenge are driven by the perceived injustice surrounding the original wrongful act as well as the harm that such actions may have on others (Aquino et al., 2001; Batson et al., 2007; Carlsmith \& Darley, 2008; Gollwitzer, 2009; Grégoire, Laufer, \& Tripp, 2010; Hogan \& Emler, 1981; Miller \& Vidmar, 1981; Solomon, 1994; Tripp, Bies, \& Aquino, 2007).

\subsection{On the perceived vs. actual consequences of taking revenge}

Up to this point, we have focused on the emotional antecedents of revenge. In that case, anger clearly plays the starring role. What about its consequences? How does taking revenge make us feel? Our intuitions suggest that revenge makes us feel good. In the English language, this idea is reflected in the familiar phrase "revenge is sweet." As McClelland (2010) and others note, the anticipated pleasure of revenge is evident in other cultures and can be traced at least as far back as Aristotle, who noted that when "human beings are angry, they feel pain, and when they avenge themselves, they feel pleasure."

Researchers in the social psychological literature have long expressed views consistent with such intuition. Some scholars frame revenge as a "mood repair" remedy, in the sense that successful punishment of the original evil-doer provides satisfaction that justice has been served (Knutson, 2004). Relevant, too, is the fact that pleasures centers of the brain become activated when people contemplate future acts of revenge (de Quervain et al., 2004; Witvliet, Hinze, \& Worthington, 2008). Consistent with these findings, revenge fantasies are often accompanied by self-reports of positive emotion (Barber, Maltby, \& Macaskill, 2005). Finally, when people are asked to reflect on the reasons why they contemplate taking revenge, a common answer is that they think it will make them feel better (Bies \& Tripp, 1995; Boon, Deveau, \& Alibhai, 2009). 
In summary, the role of anger in the dynamics of revenge would, at first blush, seem to be straightforward. People perceive an injustice, and this makes them angry. Consistent with the previously-discussed role of anger as a motivator in seeking action (Carver \& Harmon-Jones, 2009; Cottrell \& Neuberg, 2005), anger may propel people to seek retributive justice in the form of attacking the original perpetrator and/or the group with which the transgressor is affiliated. If and when justice is done, anger goes away-or, at least, subsides - and people are happy that they got their just desserts. After all, revenge is sweet, right?

However, the story is not so simple after all. In a provocative article, Carlsmith, Wilson, and Gilbert (2008) begin by making a very important observation. The "evidence" for the positive consequences of revenge is almost entirely rooted in people's expectations that revenge "should" make them feel good. In the case of the aforementioned studies by de Quervain et al. (2004) and Witvliet et al. (2008), for example, such research is more accurately seen as an anticipatory response when people imagine taking revenge.

Using the affective forecasting literature as a point of departure, Carlsmith et al. (2008) suggest that revenge may represent an interesting example of how people's predictions of their emotional experiences may not align with reality (Wilson \& Gilbert, 2003). In a clever series of experiments, Carlsmith et al. (2008) use a modified version of a prisoner's dilemma in which they studied participants' reactions to an unscrupulous "defector" who attempted to benefit financially by taking advantage of other players in the game. After a series of trials in which the defector repeatedly violated normative rules of fairness, participants were randomly assigned to one of three conditions.

Participants in the punishment condition were told that they could anonymously punish the defector via financial "penalties," effectively nullifying their ill-gotten gains. Participants in the no-punishment condition had earlier witnessed the same transgression, but were not given any opportunity for punishment (indeed, the potential for such punishment was never brought up). Participants assigned to the forecaster condition witnessed the same infractions, and-as in the case of those assigned to the punishment condition-were informed about the possibility of punishing the defector. However, instead of being given the opportunity to actually punish, they were asked to imagine that they could do so.

In this investigation - as well as in two other studies using somewhat different experimental designs_-Carlsmith et al. (2008) strategically measured 
all participants' mood at various points in the study to provide contrast between (a) participants' expectations about the hedonic pleasures of revenge, and (b) how it actually made them feel. Although this aspect of their design is somewhat complex, two findings are worth highlighting. On the one hand, forecasters clearly expected that revenge would make them feel better, consistent with stereotypical beliefs about the sweetness of such acts. However, participants that were actually given the opportunity to take revenge ended up feeling worse compared to participants in the no-punishment group.

One intriguing aspect of this story is why revenge made participants feel worse. Carlsmith et al. (2008) postulated that acts of revenge serve to "prime" people's memories of the original infraction. As Carlsmith et al. (2008) noted, this represents a paradoxical consequence of revenge. People take revenge to rectify past injustices and expect this will make them feel better. However, in the process of taking revenge, this serves to activate memories of the original infraction, which ends up making them feel worse. As Carlsmith et al. (2008) noted, anger is a "focusing" emotion, leading people to narrowly focus on events that triggered this emotion in the first place (Fredrickson \& Branigan, 2005). As a related point, anger is associated with mental rumination, such that people cannot seem to "let go" of their thoughts about the misdeeds of others (Bushman, 2002; Konečni, 1974; Rusting \& Nolen-Hoeksema, 1998). Taken in combination, these elements disambiguate why memories of the original misdeed - along with any anger associated with it - might so readily come to mind, including its ironic activation in the context of taking revenge.

\subsection{Perceptual biases in tracking very recent changes in anger}

Although the Carlsmith et al. (2008) research is provocative, it raises the proverbial why question: Why, exactly, are people so clueless about the propensity of revenge to make them feel bad (and, in particular, more angry)? This seems especially puzzling given anger is hardly a subtle emotion. Why don't people learn the emotional truth over time, and come to recognize that revenge is not sweet after all?

One possible answer is that people's memories of their own emotional history are-like many memories stored in long term memory-subject to biases and distortions. In the affective forecasting literature, this sort of explanation is used to explain why people persist in making affective forecasting errors, even in relatively "familiar" domains in which they have a great deal of experience (Wilson \& Gilbert, 2003). For example, most 
people (alas) have personal experience with romantic breakups by the time they become adults. Yet, even here, people have a hard time correctly forecasting their emotional reactions to such events (Wilson, Wheatley, Meyers, Gilbert, \& Axsom, 2000).

However, this begs another question. What would happen if we asked people to reflect upon their own changes in mood immediately following an act of revenge? According to Carlsmith et al. (2008), such acts should make people angrier relative to how they felt just a few minutes ago. Given this extremely short time frame, it seems reasonable to assume that people do have the ability to notice that they have become angry, especially given that such reactions are inconsistent with expectations (Roese \& Sherman, 2007). Yet, there is also a long line of research that shows introspection about one's own inner state is harder than one might imagine (Bem, 1972; Salancik \& Conway, 1975; Stanovich, 2013; Wilson \& Schooler, 2008). This raises the possibility that people might show a profound and rather surprising inability to correctly track recent changes in their affective state immediately after processing a revenge-related event.

\subsection{Our initial research into the revenge killing of Osama bin Laden}

Support for the latter idea was generated in a series of investigations conducted by Lambert, Peak, et al. (2014). In this research, we focused on affective reactions to an important (and, at the time of our research, relatively recent) act which was widely perceived by most citizens of the United States as an act of revenge: the assassination of Osama bin Laden in May of 2011. (The first of these three studies was conducted only a few months after this event originally occurred, with follow-up studies extending into 2013.)

To reiterate a point made earlier in this chapter, people are strongly inclined to protect the interests of the ingroup when reminded of infractions against its members. However, people belong to a multitude of ingroups and the strength of attachment to any particular collective can vary as a function of context (cf. Brewer, 1999; Hertel \& Kerr, 2001). This point was relevant to our research because our own pilot work revealed variation in terms of how Americans spontaneously described their reactions to the bin Laden assassination. Some used language reminiscent of the fiercely protective viewpoint (e.g., "I'm proud of America's ability to protect itself and smash those who would seek to harm us") associated with right-wing authoritarianism (Altemeyer, 1988), whereas others expressed misgivings about this act. This provided us an opportunity to further understand the dynamics of revenge. 


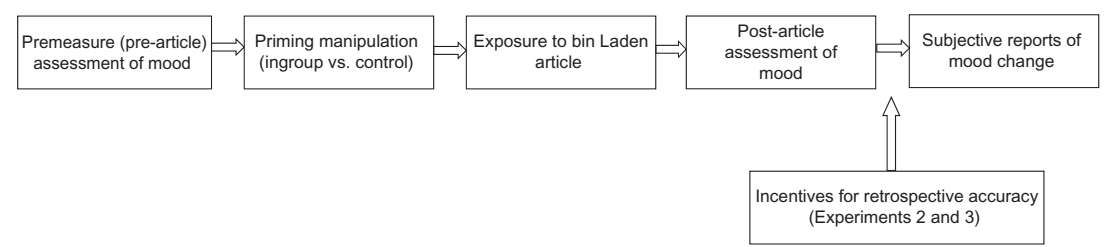

Fig. 1 Schematic outline of Lambert, Peak, et al. (2014; Experiments 1-3).

In particular, if the expected hedonic benefits of revenge are rooted in protecting ingroup interests (Fehr \& Gächter, 2002), then such expectations should be stronger if these interests are primed than if they are not.

We used these considerations in the context of a larger effort to study participants' abilities to track very recent changes in their affective state following exposure to a revenge-related stimulus. (Because the logic of this research necessitated the use of several distinct inductions/measurement blocks, Fig. 1 provides a useful visual overview of our methodology.) At the beginning of the study, we assessed participants' baseline affective state based on their response to a mood inventory. All participants then completed a short questionnaire which did, or did not, prime-relevant aspects of right-wing authoritarianism along with relevant (and highly correlated) items capturing unabashed patriotism toward the United States (e.g., Being an American is central to who I am). All participants then read a brief article about the assassination of Osama bin Laden. Notably, this article was almost exclusively focused on the death of bin Laden, with only a half-sentence reference, made in passing, to his role in the 9/11 attacks. This article was then followed by a second (i.e., "post") measurement of mood. The fact that the "pre" and "post" inventory contained the same items allowed us to form a series of parallel mood composites, pertaining to how participants felt before and after reading the article. Our main interest was objective changes in anger, but we also considered changes with respect to sadness and anxiety for the sake of providing contrast from anger.

We consider participants' subjective beliefs about their changes in mood below. However, it is first worth noting that all three of our studies revealed a strong negative shift in mood after participants read about the assassination of Osama bin Laden. Moreover, this effect (a) was always much stronger for anger compared to sadness and anxiety and (b) was not contingent on the ingroup prime noted earlier. This replicates and extends a major finding of Carlsmith et al. (2008). It is worth noting, however, that we obtained this convergence using a paradigm very different from that earlier work. For 
example, our research involved reading about an act of revenge carried out by a third party on behalf of the ingroup, whereas Carlsmith et al. (2008) were focused on more "personal" acts of revenge. Nevertheless, we too found that priming/activating a revenge-related event led participants to feel greater amounts of negative affect, despite people's lay theories about the sweetness of revenge.

Even more important, our design allowed us to ask a different question not addressed by Carlsmith et al. (2008). Would participants recognize that revenge had just made them more angry? To this end, participants completed a set of measures probing their subjective beliefs in how they think the article made them feel (e.g., compared to how you felt at the beginning of this study, to what extent did the article make you feel angry?) accompanied by scale ranging from 0 (made me feel much less angry) to 10 (made me feel much more angry). To test whether these subjective beliefs were anger-specific, participants completed parallel questions with respect to sadness and anxiety, counterbalancing for order.

All three studies revealed a remarkable failure of self-insight. Participants not only failed to recognize that the article had made them more angry; they also reported it had made them less angry! As predicted, this cathartic-like assertion about the drop of anger - which is the exact opposite of what really happened-occurred only among participants assigned to the ingroup prime condition. As we show in Fig. 2, an equally important part of this finding is that this effect was specific to anger. We replicated these effects in two follow-up investigations using a similar design, but with some improvements in the psychometric measurement of key variables (e.g., subjective change).

One of the additional pieces of leverage offered by these latter studies is that they allowed us to examine the robustness of our findings, even when participants were given extra incentives for accuracy. In one of these followups, half of the participants were given general encouragement to be accurate just prior to reporting upon their own subjective change in mood (e.g., "We are particularly interested in the extent to which people can correctly recall and track recent changes in their own mood"). However, this had no impact whatsoever on the observed pattern of results. In the last study, we used an even more blatant cue, such that half of the participants were told (again, just prior to measuring subjective change) that "Previous research has shown that revenge can sometimes lead people to think about the previous misdeeds/crimes of the person being punished. In this experiment, this suggests that prompting people to think about the assassination of Osama bin 


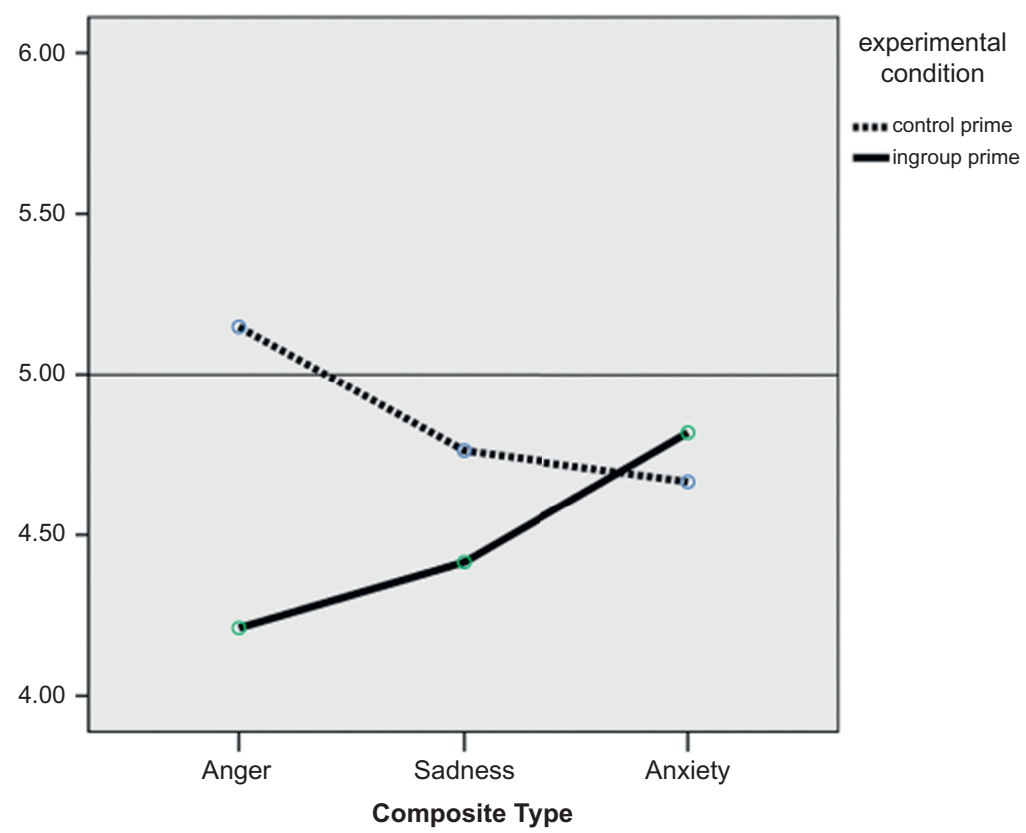

Fig. 2 Retrospective beliefs about changes in mood: Lambert, Peak, et al. (2014; Experiment $1 ; N=129)$.

Laden might remind them of the various acts of terrorism for which he was responsible, such as his role in the attacks on the World Trade Center on September 11, 2001." This manipulation, too, had no impact on participants tendency to falsely claim that revenge made them feel better (i.e., less angry).

\subsection{On the bittersweet consequences of revenge}

When taken in combination with the earlier findings by Carlsmith et al. (2008), the findings reported by Lambert, Eadeh, et al. (2014) and Lambert, Peak, et al. (2014) suggest significant lack of insight into the affective consequences of revenge. People think that revenge offers hedonic benefit, in the form of a cathartic-like drop in their own level of anger. But, in reality, the exact opposite is true: Revenge makes them more, not less, angry. Still, even in light of our own findings, we were not ready to completely give up on the idea that revenge has some affective upsides.

In particular, we found it unlikely that an important justice-restoring act like revenge would be entirely lacking in any hedonic benefit. To be clear, we believed that the propensity of revenge to make people angrier was a 
robust finding. However, our subsequent efforts were aimed at validating a more nuanced model of revenge, one that allows for a mixture of negative and positive feelings. In other words, revenge is not entirely sweet, nor is it entirely bitter. Rather it is bittersweet, in the sense that can trigger a mixture of positive and negative feelings. ${ }^{\mathrm{d}}$

For the sake of continuity, we continued to focus on the assassination of Osama bin Laden, using the same newspaper article to prime participants' memories of that event. However, these studies used a between-subjects design, as half of the participants were assigned to read the bin Laden article, whereas the other half read an affectively neutral control article. Of greater importance, we also expanded the way we measured participants' affective responses to revenge, including but not limited to the mood measures employed in our earlier work.

We shall consider the additional ways that we measured affect below. However, it is useful to first consider some findings that replicated key findings of our earlier studies. As noted above, participants in this subsequent line of work were randomly assigned to read one of two types of articles (bin Laden vs. neutral control), and in both cases, presentation of these articles was followed by the same mood inventory employed in Lambert, Peak, et al. (2014). Analyses of this inventory revealed higher levels of negative affect in the bin Laden (vs. control) condition. This is an important finding, because it affirms that revenge can actually make us feel worse, a point made by both Carlsmith et al. (2008) and Lambert, Peak, et al. (2014).

Replicating our earlier work, Eadeh et al. (2017) found higher levels of anger in the bin Laden (vs. control) condition, but this effect was also accompanied by reliably higher levels of negative affect in other domains as well (e.g., anxiety, sadness). It is somewhat unclear why we observed a broader range of negativity here compared to Lambert, Peak, et al. (2014), the latter of which found that the (actual) affective impact of revenge was almost entirely limited to anger. For present purposes, however, we again obtained strong evidence that revenge makes people feel worse when these feelings

\footnotetext{
d An interesting line of work by Gollwitzer and his colleagues (Funk, McGreer, \& Gollwitzer, 2014; Gollwitzer, Meder, \& Schmitt, 2011) appeared to show that revenge can trigger satisfaction when, in the aftermath of receiving their just desserts, the transgressor explicitly conveys remorse for his or her moral failure in a subsequent communication (e.g., "I was greedy and I now see what's wrong with that... I shouldn't be such a jerk in situations like this"). However, as we noted elsewhere, "apologies may be intrinsically rewarding in their own right, as they represent an act of contrition and may signal that future transgressions are less likely. This raises the question of whether these benefits are actually due to revenge per se, the accompanying apology, or both" (Eadeh et al., 2017, p. 28).
} 
are assessed in the context of a mood inventory. Notably, Eadeh et al. (2017) found no consistent evidence of any differences in positive mood, including a separate index of satisfaction, based on an average of happy, satisfied, and pleased.

\subsubsection{Beyond mood: Expanding our understanding of the affective consequences of revenge}

As noted earlier in this chapter, mood inventories are a popular way of assessing affect within the social psychological literature. However, it is not the only way to measure affective experience. To this end, Eadeh et al. (2017) also examined participants' spontaneous reactions in their "free write" responses to the bin Laden and control articles using Pennebaker's LIWC (Pennebaker et al., 2015; Linguistic Inquiry and Word Count) program. Briefly, LIWC offers the ability to tabulate the relative frequency of words falling into a given "linguistic category," including but not limited to emotion-related words.

As noted above, initial analyses on the actual consequences of revenge, at least in these studies, seemed to generalize beyond anger, to include anxiety and sadness. Hence, in the context of this linguistic approach, our index of negativity was based on an average of three separate indices, pertaining to anger, anxiety, and sadness. (Separate analyses of each of these indices revealed a similar pattern.) We also constructed a second linguistic index, capturing general terms of positivity that provided a reasonably good match to the items (e.g., happiness and satisfaction) that we used to construct our index of positive mood (see above). As shown in Fig. 3, the pattern of results

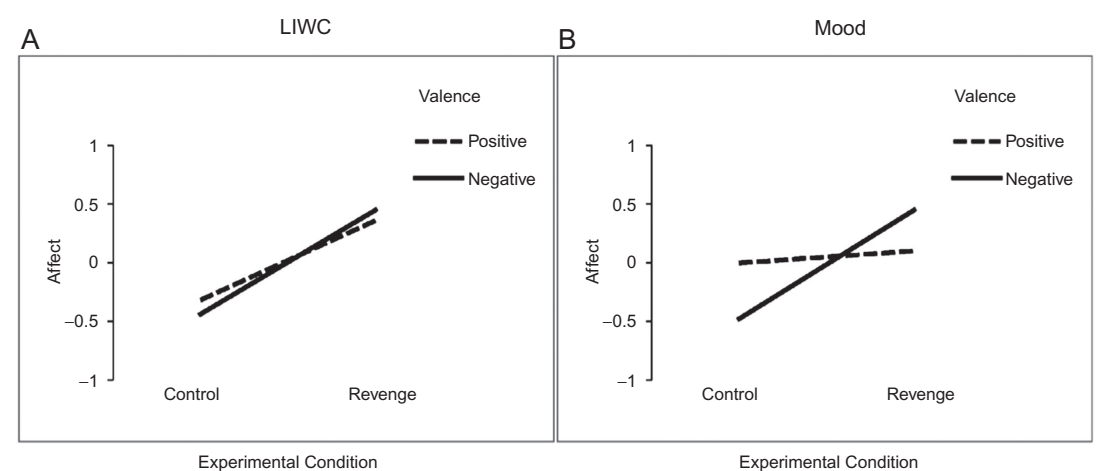

Fig. 3 Evidence for the Bittersweet model of revenge for indices derived from Linguistic Inquiry and Word Count (LIWC; left) as well as from analyses of mood (right): Eadeh et al. (2017; Experiment 1; $N=245$ ). 
using LIWC provided a striking contrast from the results obtained with more conventional mood measures. Analyses using the linguistic approach (left side) revealed higher levels of negative and positive emotion-related words if the article was about bin Laden than if it was not. In contrast, a mood-based approach (right side) revealed higher levels of negative mood, but with no change in positive mood.

\subsubsection{A consideration of two hypotheses}

These findings raise an interesting question. When the actual consequences of revenge were measured with standard mood inventories, multiple investigations (Carlsmith et al., 2008; Eadeh et al., 2017; Lambert, Peak, et al., 2014) revealed that such events consistently triggered higher levels of negative-but not positive-affect. However, when Eadeh et al. (2017) extended measurement to a linguistic analysis of participants' open-ended responses, this latter approach found evidence that revenge triggered higher levels of negative and positive affect. How could one explain this disparity?

There are two possible explanations. (Eadeh et al., 2017 considered this question in detail but we make note of the essential ideas here.) The more complicated explanation is that the linguistic approach is better suited to capturing relatively complex propositional reasoning processes (Giner-Sorolla, 1999; Wason \& Johnson-Laird, 1972). For example, consider the phrase killed dictator. Even though the two words are each negatively valenced, their overall meaning is positive. In theory, one could argue that a linguistic approach affords better leverage in capturing the kind of satisfaction that emerges when people are asked to reflect on an aggressive action toward a disliked target.

Although this is an interesting possibility, additional data supported a second - and more parsimonious - explanation. Recall that LIWC was used to analyze participants' free-response protocols when they were specifically asked how they felt about the article they had just read. Even though participants were unconstrained in terms of what they could write, these responses were made in the context of a rather direct question: How did this story make you feel? As noted in an earlier section, however, mood inventories are less direct in terms of being explicit about the referent of one's affective state. Indeed, there may not be anything "special" about using LIWC to measure the affective consequences of revenge, other than this approach provides specific information about participants' reaction to the revengerelated article. If this alternative is correct, one should obtain similar findings 
with conventional emotion measures, when participants are directly probed for their affective response to their assigned article.

Results from our last experiment provided strong support for this second explanation. After reading the target article, participants were presented with a randomized series of 12 emotion terms (comforted, happy, sad, angry, satisfied, pleased, anxious, proud, mad, relieved, dejected, nervous). For each item, participants appraised how the article made them feel, along a scale ranging from 0 (not at all) to 7 (very much so). Analyses of these emotion ratings yielded a pattern virtually identical to the LIWC analyses. That is, both analytic approaches showed evidence of positive and negative responses to the revenge vs. control article. Although the differences for positive and negative reactions were significant, both analyses revealed larger effect sizes for the positive (vs. negative) reactions. In other words, there was no evidence that the hedonically positive reactions to revenge were smaller than the negative reactions.

\subsubsection{Summary}

Although some aspects of these findings are complex, they offer a very important implication about the affective consequences of revenge. Revenge does have the potential to elicit positive and negative feelings. In order to observe this "bittersweet" aspect of revenge, however, one needs to use an approach to measuring affect that is different from conventional mood measures. As we note above, we employed two different types of measures that afforded somewhat more direct assessment of how participants felt about the revenge-related article. One of these involved linguistic analyses of participants' "free write" passages and another probed these feelings using direct measures of emotion. Although these two methods are (obviously) different from each other, they both yielded the same conclusion, namely, that revenge has the capacity to trigger negative and positive feelings.

These findings raise larger questions as to how, exactly, measures of mood differ from more "referent-specific" measures of affect. We believe this is an important question, and future work is clearly needed. In the context of research on revenge, however, one thing is quite clear: Revenge does have a paradoxical element to it (i.e., it makes us feel bad), but it also makes us feel good. (For a converging line of evidence regarding the bittersweet nature of revenge, see Chester \& DeWall, 2015, 2017.) These two elements appear to be reliably captured when investigators directly ask participants for their reactions to revenge, as opposed to assessing their affect in a general manner (as is the case for mood inventories). However, this does not mean 
mood inventories are scientifically "suspect" or unreliable markers of affective experience. On the contrary, they can be very useful in a variety of different paradigms, including the line of work we describe next.

\section{Part V: On the nature of affordances}

Gibson was a well-known cognitive psychologist who made many contributions to ecological psychology (e.g., Gibson, 1977, 1979) and is credited for introducing the concept of affordances. Although the concept of affordances is complex (Greeno, 1994), the basic idea is that affordances facilitate action sequences when we want to do something. Affordances in our environment "are what it offers the animal, what it provides or furnishes" (Gibson, 1977; p. 67, emphases in original). In one of Gibson's own examples, mailboxes serve as affordances to the action of a mailing a letter. However, countless stimuli serve as affordances when we want to do something. Blankets afford warmth. Ladders afford climbing. Handles afford grasping.

Gibson was famously averse to theorizing about internal processes (Norman, 1999) and his theory makes no explicit reference to constructs familiar to social psychologists (e.g., attitudes). Nevertheless, the affordance construct - defined broadly-provides an elegant way of conceptualizing context-specific changes in how people evaluate stimuli in their environment. For example, that old blanket in your car that ordinarily elicits disdain is likely to have greater appeal if one is stuck in subzero weather with a stalled engine. In other words, old blankets are not "good" or "bad": their value is determined by their utility in meeting salient goals.

\subsection{Threats represent problems that need fixing}

Our extension of the Gibsonian concept of affordances is useful when considering psychological research on threat. The Oxford English dictionary defines threat as a "person or thing likely to cause damage or danger." Of course, threats come in many shapes and sizes. Some threats (e.g., tornados) are acts of nature, others are caused by human error (e.g., a fire caused by improper wiring), and yet others reflect malevolent intent (e.g., burglars breaking into a home). However, nearly all threats share one element: they motivate people to seek out solutions to the problem at hand. In some cases, one can achieve this goal on one's own. Other solutions require collective action. In the latter case, we tend to call on people perceived as effective in dealing with the problem. When a fire emerges in the basement, one calls the fire department, not the plumber. 


\subsection{Perceived affordances in politics}

Research within and outside of the United States has shown that people have stable beliefs about issues that conservatives vs. liberals are good at "fixing" (Janoff-Bulman, 2009; Petrocik, 1996; Seeberg, 2017). This idea is sometimes defined as "issue ownership," because it applies to beliefs about the effectiveness of political parties in solving different issues (Petrocik, 1996). However, the consistency of findings across cultures (Seeberg, 2017) suggests that these dynamics go beyond beliefs about political party per se (e.g., what Republicans are "good" at). Instead, the deeper issue is that ideologies seem to be associated with different types of needs and goal states.

Most relevant for present purposes, one of the salient features of conservatism is an emphasis on "society's protection and security" (Janoff-Bulman, 2009 , p. 121), especially in the context of defending the nation from aggressive external threats (Seeberg, 2017). One aspect of this dynamic is reflected in stereotypic views about political parties. For example, cross-cultural studies find that conservative (vs. liberal) parties are perceived as more effective in defending against national security threats, including terrorism (Newport, 2014). Again, however, this effect goes beyond mere reputation of conservative parties. Instead, it is best understood as reflecting a facet of conservatism, one that is associated with an aggressively oriented "get tough" approach to punishing those that threaten the ingroup (see, especially, Alker \& Poppen, 1973; see also Carroll, Perkowitz, Lurigio, \& Weaver, 1987; Knight, 1999). In the context of terrorist threat, this facet of conservatism is reflected in what is often referred to as hawkishness, defined here as a militaristically "aggressive" response to actual and suspected terrorists acts from external threats.

\subsection{Hawkishness as a perceived affordance in the fight against terrorism}

A central prediction of our model is that the psychological appeal of hawkishness is greater if terrorist threat is salient than if it is not. Here we refer to general positivity associated with this component of conservatism, and greater support for actions and policies of the government (e.g., increased military funding) which might otherwise elicit disdain. In the context of our model, this prediction reflects the status of hawkishness as a perceived affordance in one's effort to address a particular problem linked to a specific type of threat (here, terrorism). Stated differently, such threats can stimulate an action-oriented/problem-solving mode of processing in which people 
positively appraise elements in their environment that are perceived as effective "tools" for responding to the relevant threat. This process has implications for the way people appraise the value of general policies (e.g., hawkish vs. dovish responses) and can lead people to prefer certain types of politicians over another.

\subsection{Implications for anger}

Earlier in this chapter, we alluded to the important role of anger as an actionoriented feeling that motivates people to seek ways of rectifying injustices. In the context of our affordance model, therefore, we predicted that the activation of anger for one particular type of threat - terrorism-would play a central role in enhancing the value of one aspect of conservative ideology, namely, a militaristically aggressive (i.e., hawkish) approach to dealing with this particular problem. In the section to follow we consider three separate lines of work showing support for this idea, with all confirming the central role of anger.

As we shall show, our initial research (Lambert et al., 2010) involved appraisals of a sitting president (George W. Bush) as a function of whether participants had earlier been primed with memories of the 9/11 attacks. A subsequent line of work (Eadeh et al., 2018) continued to focus mostly on the threat of terrorism, but we used a combination of fictional and real politicians in order to generate more precise conclusions as to the role of political affiliation (i.e., whether the target belonged to the Republican or Democratic party) in these dynamics. However, this work-as well as an additional line of studies by Eadeh and Chang (in press)-extended our focus beyond terrorism per se in order to show that different types of threat can have very different types of ideological consequences.

\section{Part VI: Threat, anger, and political attitudes}

Shortly after the attacks of $9 / 11$, the approval ratings of George W. Bush soared nearly 40 points, to $90 \%$ (Hetherington \& Nelson, 2003). This represents an example of a rally 'round the flag effect, a concept formally introduced by John Mueller (1970). According to Mueller (1970), rally effects are caused by events that (a) are international in scope; (b) involve the United States and particularly the president; and (c) are "specific, dramatic, and sharply focused" (p. 209). These criteria would include not only aggressive actions toward and/or by the United States, but also events such as military 
victories or other dramatic accomplishments connected to the president (e.g., major scientific and/or diplomatic accomplishments).

After reviewing the available literature on rally effects, Baker and O'Neal (2001) suggested that the antecedent conditions laid out by Mueller (1970) were too broad. Baker and O'Neal (2001) posited that rally effects are reliably produced only by "military" crises involving imminent or actual attacks directed toward and/or by the United States. In line with this view, there are only a handful of well-documented rally effects besides the attacks of 9/11, and all of these are consistent with the Baker and $\mathrm{O}^{\prime} \mathrm{Neal}$ 's perspective. These include the surprise attack on Pearl Harbor in 1941, the Bay of Pigs crisis in 1962, the entry of the United States into the Gulf War in 1991, and the invasion of Iraq in 2003.

Although Baker and O'Neal (2001) did not explicitly focus on affect, their conceptualization suggests that anger plays an important role in enhancing the popularity of the American president. In other words, given the strong link between rally effects and "aggressive" events (e.g., major attacks toward and/or by the United States), this logically suggests that anger may be central to driving these attitudinal changes. Several programs of research provide converging evidence for this point. For example, anger (but not fear, anxiety, or sadness) is associated with positive appraisals of "hawkish," high-risk policies of the government, including the decision to launch military strikes as part of an antiterrorism campaign (Lerner et al., 2003; Sadler, Lineberger, Correll, \& Park, 2005; Skitka, Bauman, Aramovich, \& Morgan, 2006). Although previous studies focused on policy preference (rather than presidential approval), launching military strikes are precisely the type of decisions made by war-time presidents, and this research has obvious relevance to the dynamics of rally effects.

\subsection{Experimental studies of the impact of the 9/11 attacks on political attitudes}

The importance of anger was also shown in a series of experimental studies conducted in our laboratory (Lambert et al., 2010). In this work, participants were randomly assigned to conditions in which they either were, or were not, reminded of the 9/11 attacks. These reminders came in the form of either dramatic film footage of the destruction of the World Trade Center (Experiments 1 and 2) or through prompting participants to write about their own thoughts and feelings regarding the attacks (Experiment 3).

In this research, we were primarily, but not exclusively, interested in studying the impact of terrorist threat on attitudes toward then-president 
George W. Bush. In Experiment 1, we formed four separate multi-item attitude indices, which assessed (a) attitudes toward Bush, (b) support for the ongoing war in Iraq and Afghanistan, along with appraisals of other "hawkish" attitude objects (e.g., support for a mandatory draft), (c) general evaluation of patriotic symbols (e.g., the American flag) and (d) a general measure of political attitudes, scored such that higher numbers indicated favorable reactions toward aspects of social conservatism (e.g., prayer in public school, feelings about abortion).

We consider the role of anger shortly, but it is useful to show the pattern of means as a function of whether participants were assigned to the threat vs. control condition. As shown in Fig. 4, participants expressed more favorable attitudes toward the first three indices when primed with terrorist threat (vs. control). Yet, no reliable changes were observed with respect to attitudes toward social conservatism. (The null effect obtained with the latter index is important, as we shall show later.) We replicated these effects in two additional studies.

\subsubsection{On the independence of threat-driven changes apart from individual differences}

All of the studies reported by Lambert et al. (2010) drew from a convenience sample of undergraduates at a moderately liberal university. Hence, we

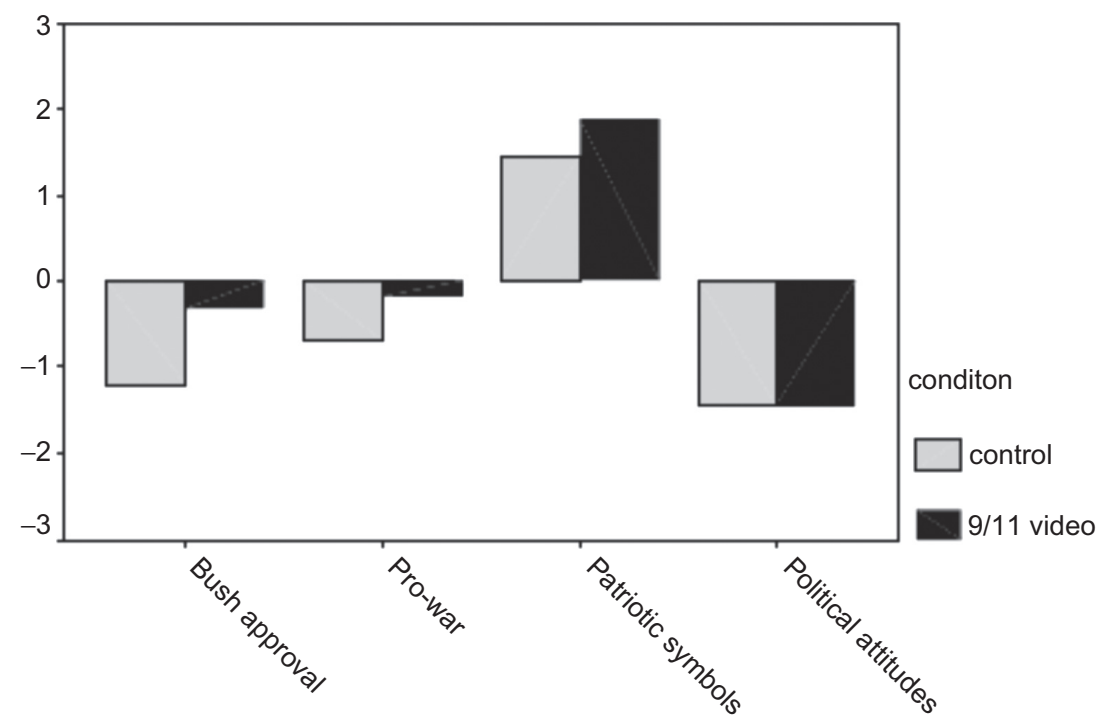

Fig. 4 Effects of priming terrorist threat on attitudes: Lambert et al. (2010; Experiment 1; $N=136$ ). 


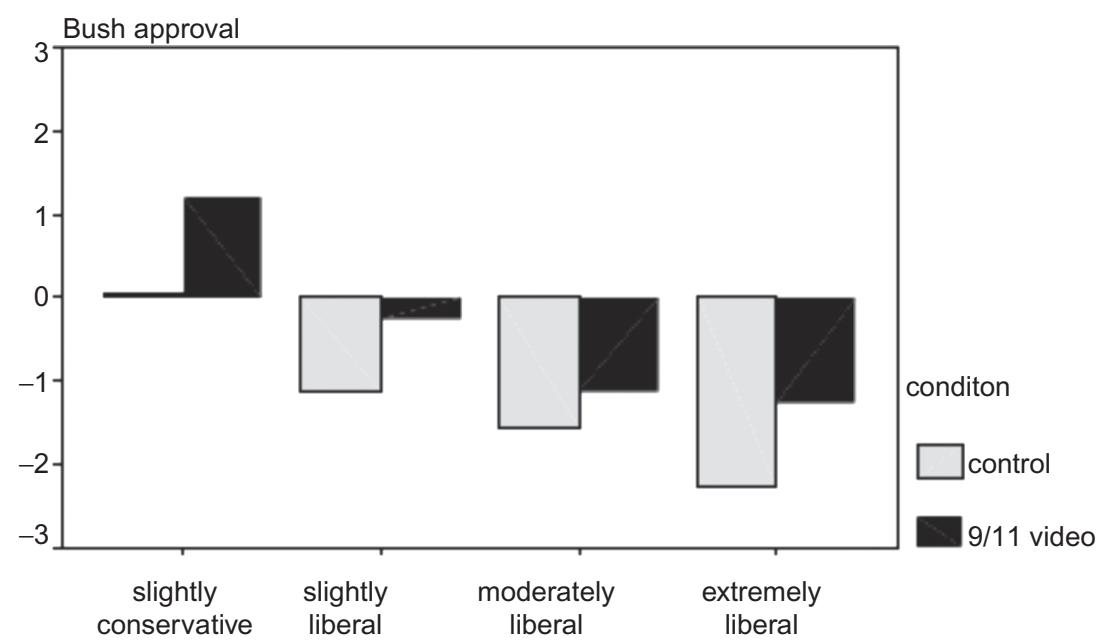

Fig. 5 Effects of terrorist prime on support for President Bush as a function of participants' ideology: Lambert et al. (2010; Experiment 1; $N=136$ ).

anticipated that our samples would contain few participants with moderate or strongly conservative views. (This was confirmed by examining participants' scores on a measure of authoritarianism - a popular index of conservatism - at the beginning of the study, prior to condition assignment.) In other research paradigms, this restricted range would be a liability. In our case, this arguably constituted a strength, in the sense that it allowed us to examine whether terrorist threat would boost support for a very conservative president, even among participants for whom this person would ordinarily elicit a great deal of disdain.

We tested this proposition formally in the context of regression, but the implications of these analyses are most clearly shown in Fig. 5, which displays the pattern of means for the threat vs. control as a function of participants' own ideology, ranging from extremely liberal to slightly conservative. As seen here, we observed "additive" effects of the threat manipulation, over and above any effects attributable to participants own ideology. Our subsequent work, to be described in a latter section, found an analogous pattern using a much more ideologically diverse sample of adult participants. These and other findings from our laboratory should not be taken to imply that individual differences are not important. As seen in Fig. 5, for example, participants own ideological beliefs were predictive of how they felt about Bush. The more relevant point is that in this work, as well as in our subsequent 
studies, we find that the situation-specific impact of threat on participants' political attitudes occurs independent of, and in addition to, these individual differences. $^{\mathrm{e}}$

\subsubsection{Consideration of affective mediation}

To no one's surprise, the manipulation of terrorist threat (vs. control) in Lambert et al. (2010) elicited significantly higher levels of anger, fear, and sadness. Of much greater importance, tests of affective mediation revealed that anger - but not anxiety-led to more favorable attitudes toward George W. Bush, and to greater support for the war in Iraq/Afghanistan. Indeed, in the case of anxiety, we found a small tendency for this emotion to be associated with less favorable attitudes. This pattern of findings, displayed in Fig. 6, was replicated in two additional studies, one of which used a very different methodology of priming terrorist threat. ${ }^{\mathrm{f}}$

The experimental results reported by Lambert et al. (2010) are consistent with but also provide causal leverage on a largely correlational body of work showing the propensity for terrorist-fueled anger to induce a "get tough" stance regarding appraisals of hawkish and other related "aggressive" policies (Sadler et al., 2005; Skitka et al., 2006). Moreover, conceptually analogous

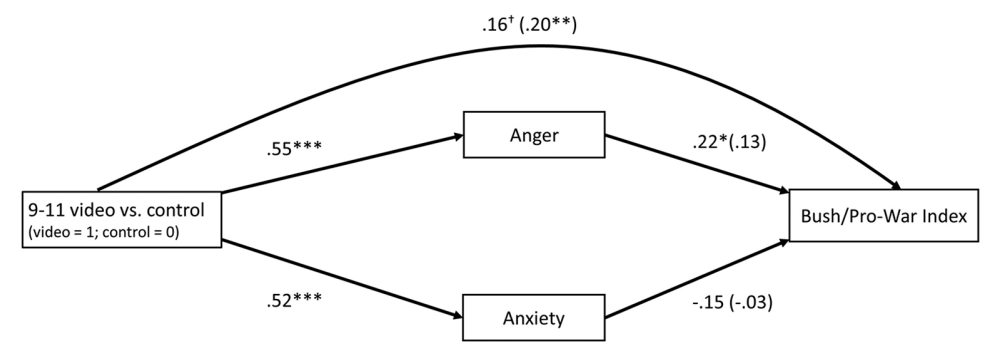

Note: All values shown are standardized beta coefficients; values in parentheses reflect the simple relation of the variables in question, not controlling for the other emotion. $+p<.10 ; * p<.05 ; * * p<.01 ; * * * p<.001$

Fig. 6 Mediational analyses for Lambert et al. (2010; Experiment 1; $N=136)$.

\footnotetext{
e These findings mesh nicely with the broad-band surge of support enjoyed by President Bush in the immediate aftermath of the 9/11 attacks among liberals and conservatives alike.

${ }^{\mathrm{f}}$ Mediational analyses reported in the context of the Lambert et al. (2010) investigation (see Fig. 6) predated recent advances in statistical software to permit formal analyses of two or more mediating variables. All other mediational analyses presented in this chapter are generated by PROCESS (Hayes, 2013).
} 
effects have been obtained in other countries in the context of other terrorist attacks (Halperin, Russell, Dweck, \& Gross, 2011; Reifin-Tagar, Frederico, \& Halperin, 2011; Reifen-Tagar, Morgan, Halperin, \& Skitka, 2014). In other words, these findings do not appear to be a uniquely "American" phenomenon, but instead generalize beyond the specific dynamics of the 9/11 attacks.

\subsubsection{Questions raised by the Lambert et al. (2010) research}

The findings reported by Lambert et al. (2010) are provocative, but certain aspects of these results are open to multiple interpretations. For example, George W. Bush was not only a sitting president at the time those studies were conducted, but he was also a hawkish Republican. This fact, alone, raises some important questions: Are these effects specific to presidents, or would these generalize to other politicians? And, if these effects did generalize, would they be constrained only to Republicans, or is the most critical factor the "hawkish" status of the target? The studies to be described below were designed to provide answers to these and other questions.

\subsubsection{A note on sadness and fear}

Terrorist attacks are likely to trigger other negative emotions besides anger, and these other emotions may carry different consequences. In the case of sadness, experimental activation of this feeling state can elicit a "careful" processing style, characterized by lower confidence and a motivation to avoid impulsive decisions (Huntsinger et al., 2014; Lambert et al., 1997; Schwarz, 2012). Given this contrast to the known consequences of anger (see earlier discussion), this leads to an interesting prediction: Following the activation of terrorist threat, analyses should reveal evidence of "oppositional mediation" (Kenny, 2017), in the sense that the concomitant activation of two positively correlated emotions — anger and sadness - could exert opposite effects on the psychological attractiveness of hawkish policies.

Predictions for fear were less clear. By its very nature, fear is associated with a heightened sense of danger, and can motivate people to flee from harm. To this extent, fear in the context of terrorist threat might lead to more favorable appraisals of hawkish policies, if these are perceived as a way of insuring the safety of the ingroup. However, research by Lerner and colleagues shows that, unlike anger, fear is associated with lower tolerance of risk and lower confidence. Given that hawkish responses to terrorist threat are inherently risky (Lerner et al., 2003), this suggests that any feardriven appeal of hawkish policies might be balanced out by the association of fear with risk-aversive processing style. 


\subsubsection{Eadeh et al. (2018; Experiment 1)}

The overall design of this study $(N=564)$ was similar to the Lambert et al. (2010) investigation but differed in some respects. (We present the methodology of this study in some detail, because the remainder of the studies, below, used a similar set of procedures and materials.) As in our earlier work, participants were randomly assigned to a terrorist threat vs. control condition, but instead of having participants evaluate a real politician, they were presented with a description of a fictional (but believable) politician who identified as a Republican or a Democrat. In all cases, participants were presented with a 100-word speech made by the target, which conveyed a hawkish or dovish policy with respect to terrorist threat. Hence, the design of the study was a 2 (prime: terrorism vs. control) $\times 2$ (target party: Republican vs. Democrat) $\times 2$ (type of speech: hawkish vs. dovish) factorial design.

In this study, terrorist threat was primed by having participants "think about the threat posed by the terrorist organization commonly referred to as the Islamic State (i.e., 'ISIS'/'ISIL')" with instructions to "write down, as specifically as you can, the kind of threat that this group poses to the United States." Participants assigned to the control condition were asked to "describe the mundane events that occur during your typical day," a task used before in the service of providing an affectively neutral baseline condition (see Lambert, Eadeh, et al., 2014; Lambert et al., 2010). Immediately following these respective tasks, participants completed a standard mood inventory. Aside from serving as a manipulation check (to ensure the terrorist prime was taken seriously), this inventory allowed us to conduct tests of affective mediation, with the prediction that such effects would arise with anger, but not fear or sadness. In all cases, these affective states were operationalized on the basis of multi-item composites. In the case of anger, for example, our composite was based on an average of participants' ratings of angry, mad, irate, and hostile.

After the mood inventory, participants evaluated a fictional (but ostensibly real) politician. In all cases, information about the target person was presented on a single screen. The top of the screen contained a small "headshot," along with his name (Senator William Cunningham) and a one word-description of his political affiliation ("Democrat" or "Republican"). Immediately below, we presented the text of a speech made by this politician, conveying either a very hawkish or very dovish policy. Our target description was deliberately designed so that the speech was the only substantive information participants had about the target. This point becomes important in the context of our subsequent studies. 
On the next page, participants evaluated a series of standard Likert-type questions designed to assess their impression of the target. Some of these items pertained to general impressions, whereas others referred to his speech and/or leadership skills. In all studies, principal components analyses revealed a one-factor solution on which all of these items loaded highly. Hence, a general positivity index averaging across all items was formed, after reverse scoring as necessary.

This study was designed to test the generalizability of the attitudinal consequences of anger when activated in the context of terrorist threat. If anger generally leads participants to find hawkishness more appealing, one might expect more favorable appraisals of the hawkish (vs. dovish) targets, regardless of their political affiliation. As we show in Fig. 7, this is what the data showed. In the case of the hawk, participants evaluated this person more favorably if they were assigned to the threat vs. control condition. In contrast, this effect was reversed for the dovish target. This effect was responsible for a significant interaction of prime and target type. There was no evidence that these effects were qualified by political party. In other words, participants liked the hawkish target more (and the dovish target less) regardless of whether the target was described as a Republican or Democrat.

Of greater relevance was the role of anger in mediating these effects. These analyses are shown for participants that judged the hawk (Fig. 8, top) and those that judged the dove (Fig. 8, bottom). Significant evidence

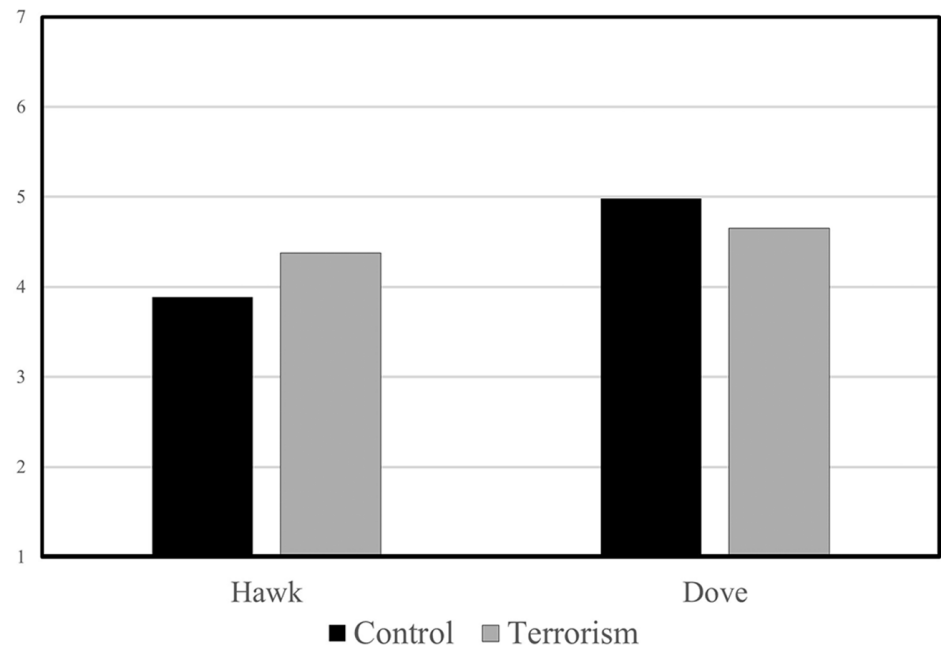

Fig. 7 Interactive effects of terrorist threat on judgments of hawkish vs. dovish politicians: Eadeh et al. (2018; Experiment 1; $N=564)$. 

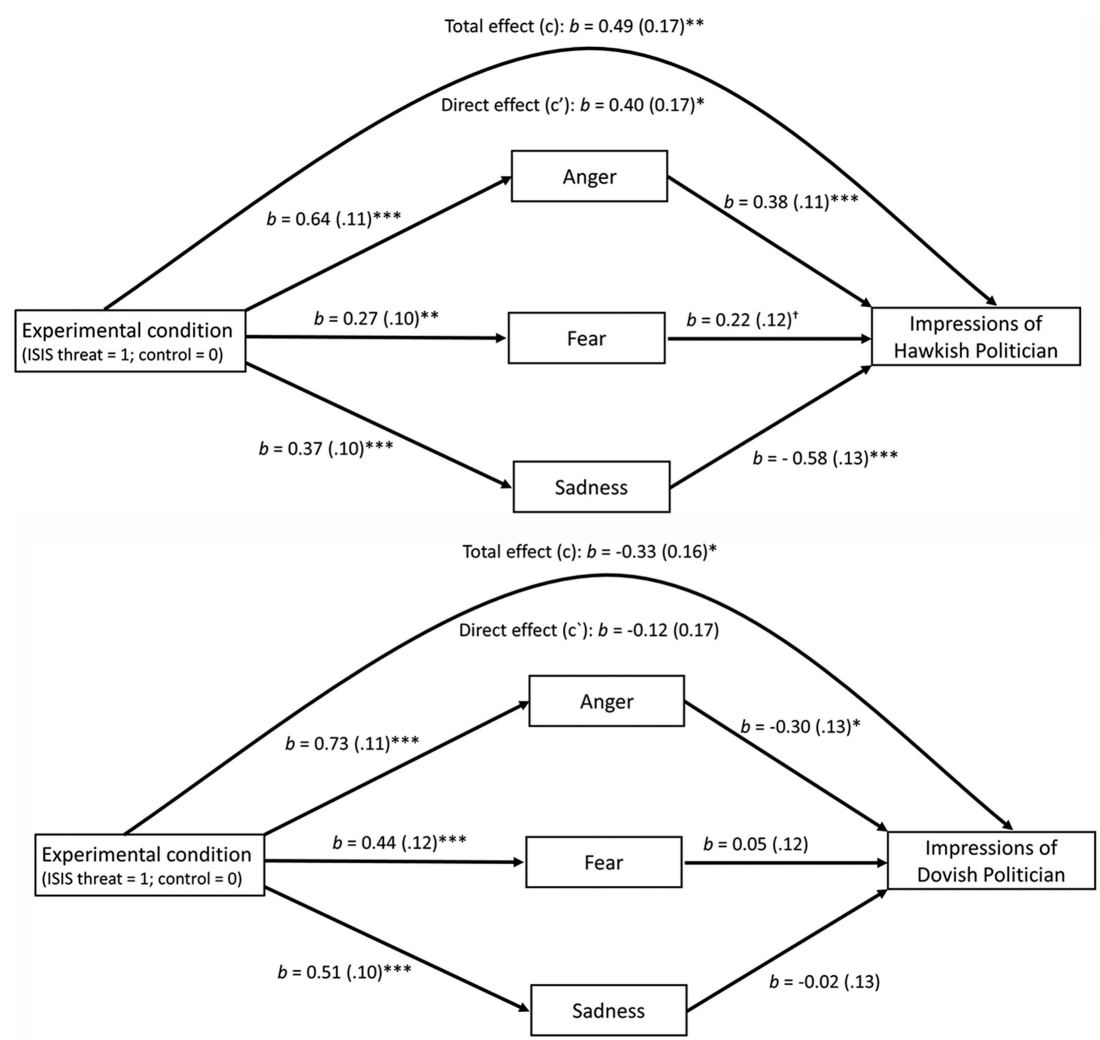

Note: Values in parentheses represent standard error estimates.

$+p<.10 ;{ }^{*} p<.05 ;{ }^{* *} p<.01 ;{ }^{* * *} p<.001$

Fig. 8 Affective mediation for politicians espousing hawkish (top; $N=279$ ) or dovish (bottom; $N=285$ ) speech: Eadeh et al. (2018; Experiment 1).

of mediation was found for anger in both cases. As predicted by our model, the direction of these effects was different for the two targets (positive for the hawk, negative for the dove). The only other evidence of mediation emerged with sadness. When participants evaluated the hawkish target, sadness-related feelings led to more unfavorable reactions toward this person, an effect that directly opposed the effects observed with anger. No reliable effects emerged with fear in either analysis.

\subsubsection{Eadeh et al. (2018; Experiment 2)}

One particularly provocative aspect of the aforementioned study is that terrorist threat indirectly (via anger) led to more favorable reactions to a Democratic hawk (vs. a Democratic or Republican dove). As we note in detail 
below, one reason these effects were so interesting is that hawkish policies are relatively inconsistent with positions stereotypically associated with Democrats. To provide greater evidence for the replicability of this finding, we conducted a direct replication with a separate group of participants $(N=232)$. This design of this study was identical to the first experiment, except that all participants evaluated the hawkish Democrat. These findings replicated all of the key findings reported above. ${ }^{\mathrm{g}}$

\subsubsection{Eadeh et al. (2018; Experiment 3)}

In the two previous experiments, political affiliation played no discernable role in the process by which anger influenced appraisals of the hawkish vs. dovish targets. That is, anger boosted support for hawks (and diminished support for doves) regardless of whether the target was a Republican or Democrat. However, political affiliation was conveyed only in passing, by one word appearing at the top of the biographical sketch. Perhaps this explains why the content of the speech played a more important role in our findings compared to party membership of the target.

As a more general point, the way we presented information about the politician could be criticized as rather artificial. (Indeed, the target was artificial in a literal sense, as he did not exist in reality.) As is usually the case with laboratory studies, the advantages of using hypothetical vignettes are considerable, allowing researchers experimental control and leverage on causality that are otherwise less attainable when studying real people. However, these benefits are balanced out by some important costs, including a lack of external validity. In our particular case, these latter concerns are mitigated as our recent findings were consistent with Lambert et al. (2010), where participants rated then-president George W. Bush. Nevertheless, studying real politicians unquestionably offers advantages not afforded by the use of hypothetical vignettes.

These considerations led to our next study, which focused on Wesley Clark, a real-life political figure. In many ways, Mr. Clark provided us the

\footnotetext{
g In an additional study run with a separate group of participants, we found that Republican targets were rated as more typical if they were hawks than if they were doves, with the reverse pattern for Democratic targets. Closer examination of this interaction revealed that it was mostly driven by especially low typicality ratings of the Republican doves. These data were not unexpected, but they show that induction of threat did not simply result in a preference for typical targets (see Schimel et al., 1999). If participants used typicality per se as a criterion for evaluating the targets under threat, we should have found that priming terrorism should have selectively resulted in lower ratings of this one target in particular (i.e., the dovish Republican), but this clearly did not happen.
} 
perfect opportunity to test important aspects of our theoretical framework. Clark was a highly-decorated military officer, who served with distinction in the Vietnam War, held leadership positions in the wars in Bosnia and Herzegovina, and was the Supreme Allied Commander during the military campaign in Kosovo. Although Clark's military career predated the United States' recent focus on terrorism, his distinguished and decades-long association with the military easily establishes his credibility as a person skilled at aggressive defense of America's interests. In short, Wesley Clark is the prototypical embodiment of a hawk.

However, Wesley Clark is also a Democrat. More precisely, Clark became an active member of the Democratic Party following his career in the military. One prominent aspect of his post-military career was his bid for the presidency in 2004, running as a Democrat. Clark did not secure his party's nomination (losing to John Kerry) but his campaign was a serious one that (initially, at least) attracted a fair amount of attention. Taken in combination with his distinguished military career, Clark's affiliation with the Democratic party provides a real-life analogue to the fictional hawkish Democrat that we studied in our two earlier investigations.

More importantly, the trajectory of Clark's career also provided us with an opportunity to test an interesting prediction. We hypothesized that priming terrorist threat could trigger different reactions to Clark, depending on the extent to which the target information emphasized his affiliation with the Democratic party. In all cases, participants were provided with a photograph of Clark in full military uniform and the same opening paragraph describing Clark's distinguished military service:

\begin{abstract}
Wesley Kanne Clark, Sr. (born December 23, 1944) is a retired General of the United States Army. He attended West Point and graduated in 1966 as valedictorian. He served 34 years in the Army, receiving many military decorations and the Presidential Medal of Freedom. Clark commanded Operation Allied Force in the Kosovo War during his term as the Supreme Allied Commander Europe of NATO from 1997 to 2000. He was also part of the 1st infantry division and worked as a staff officer during the Vietnam War, which earned him a bronze star.
\end{abstract}

Participants were also presented (on the same page) with a second paragraph, describing aspects of Clark's post-military career. In nearly all respects, this information was identical for all participants. However, half of the participants were given more specific information conveying Clark's personal commitment to liberal values, whereas the other participants did not see this information. The passage in question is indicated in italics 
below (this emphasis was not made in the passage that was actually presented to participants):

After retiring from the military, he engaged in a public speaking tour around the
country and wrote two books. Clarkjoined the 2004 race for the Democratic Party
presidential nomination as a candidate in 2003, but withdrew from the primary
race in 2004. Clark leads a political action committee which is used to support
Democratic Party candidates. Clark has stated that he decided he was a
Democrat because "I was pro-affirmative action, I was pro-choice, I was
pro-education ... I'm pro-health care ... I realized I was either going to be
the loneliest Republican in America or I was going to be a happy Democrat."
He currently resides in Little Rock, Arkansas with his wife.

In summary, participants in both conditions were informed that Clark spent the majority of his career in the military. We predicted that mere association with the Democratic Party, even if it involved running for president, would not undermine Clark's status as a military leader. Therefore, we predicted terrorist threat, via anger, would lead to positive appraisals of Clark, provided that information about his ideological commitment to that party was absent. Demonstration of this effect is important, as it would provide converging evidence to our first two studies, such that affiliation with the Democratic Party would not inevitably nullify the tendency for anger to boost support for a strong hawk.

At the same time, our design allowed us to show how easily this effect could be eliminated or even reversed. Objectively, information about Clark's ideological commitment to the Democratic Party did not contradict his proven abilities as an effective military hawk. Yet, it was inconsistent with stereotypic beliefs of what hawks are "supposed" to be like. Such information was expected to undermine perceptions of Clark as a reliable "affordance" (Gibson, 1977) in the context of terrorist threat. As such, we expected that mediational analyses would reveal null or possibly even negative contributions of anger following terrorist threat, the reverse of what was expected to occur in the other condition.

We tested these predictions in the context of a study $(N=359)$ employing the same terrorist threat condition used in the two preceding studies, while also varying the nature of the information presented about the target. Initial ANOVAs revealed a significant interaction of terrorist prime and target type: participants assigned to the threat (vs. control) condition expressed more favorable impressions of General Clark when his ideological commitment to the Democratic party was absent $(M s=5.47$ vs. 5.20$)$ but this pattern was reversed when this commitment was present $(M s=5.39$ vs. 5.61$)$. 

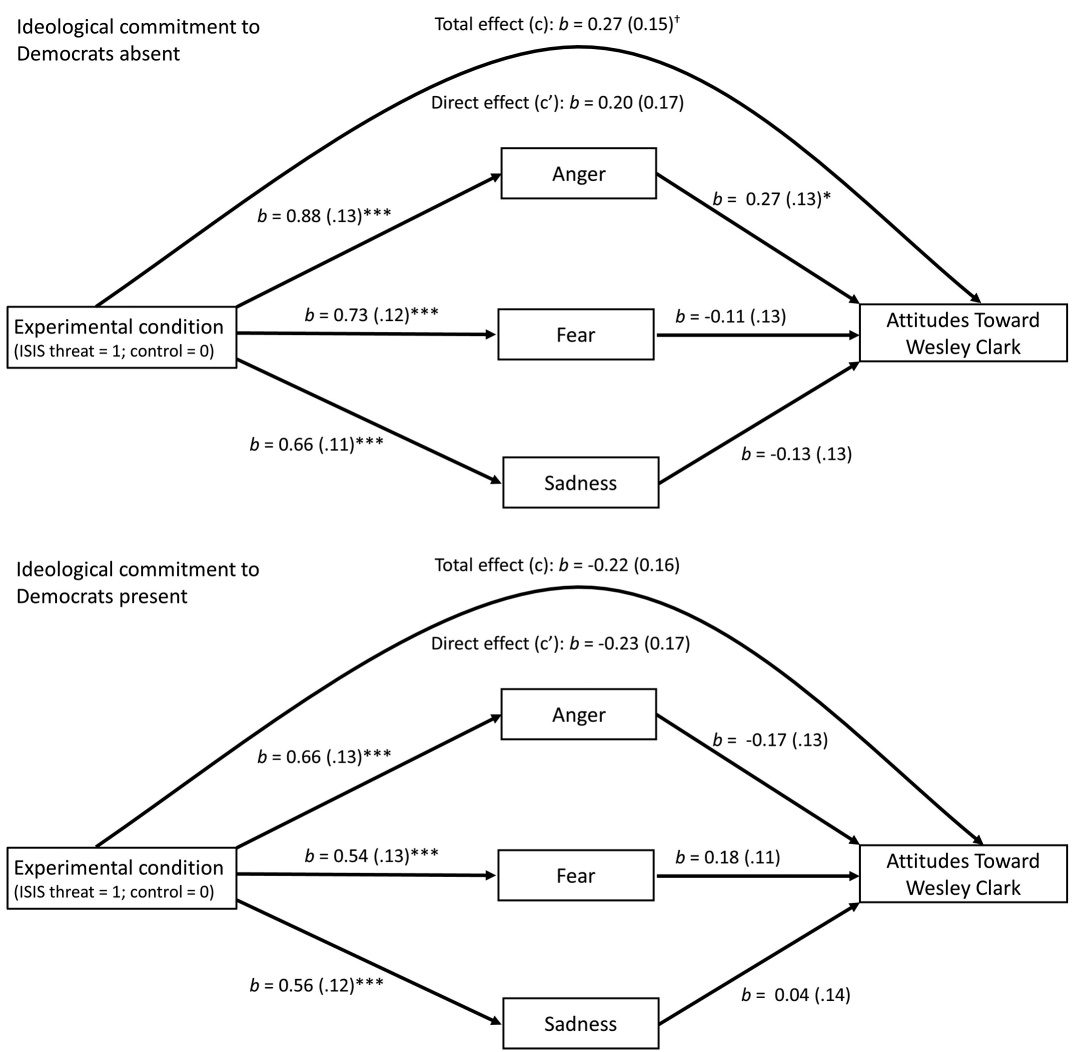

Note: Values in parentheses represent standard error estimates.

$+p<.10 ;{ }^{*} p<.05 ;{ }^{* *} p<.01 ;{ }^{* * *} p<.001$

Fig. 9 Affective mediation for judgments of Wesley Clark with ideological commitment to the Democratic party absent (top; $N=177$ ) vs. present (bottom; $N=182$ ): Eadeh et al. (2018; Experiment 3).

Once again, our main interest was in affective mediation of these effects. First consider the pattern when ideological commitment was absent (Fig. 9, top). As seen here, the only evidence for significant mediation arose for anger, with higher levels of anger predicting more favorable reactions toward the target. This effect is consistent with our framework and extends findings obtained in Experiments 1 and 2. There was a weak tendency for sadness to elicit more negative appraisals of the target (an effect seen in our first two investigations), but this effect was not reliable in this case. No reliable effects were found for fear.

Turn next to the findings when ideological commitment to the Democratic party was present (Fig. 9, bottom). In contrast to the other target, there 
was no evidence that anger boosted support for this target. Indeed, there was a tendency for anger to be associated with negative appraisals of the target. The difference in these anger-related effects suggests the presence of moderated mediation, such that threat-driven anger in guiding target appraisals (i.e., the $b$ path) was reliably contingent on target type. Follow up analyses formally confirmed this to be the case. Parallel tests of moderated mediation revealed no reliable effects in the case of sadness or fear.

\subsubsection{Summary}

These effects replicate key aspects of our previous findings but offer a very important additional insight. The activation of anger following terrorist threat increases the psychological appeal of hawkish policies, regardless of their political stripes, provided this information is downplayed in the context of the impression formation task. We showed this effect three times, twice with a hypothetical target, and a third time with a real-life hawkish Democrat in the form of Wesley Clark. However, when ideological commitment to the Democratic Party is made salient, this completely eliminates the effect.

\subsubsection{Eadeh et al. (2018; Experiment 4)}

Our affordance model takes a neo-Gibsonian approach to studying the ideological consequences of threat, insofar as we predict that threat will enhance the favorableness of certain ideological beliefs, provided that they are relevant to the problem needing to be "fixed." This aspect of our model suggests that the activation of terrorist threat should have a narrow impact on appraisals of politically-themed attitudes: namely, more favorable appraisals of hawkish-related attitude objects. However, terrorist threat should not reliably influence appraisals of other political attitudes, such as those related to abortion or attitudes toward LGBT rights.

As noted earlier, we found some evidence for this specificity in the context of the Lambert et al. (2010) investigation. In Experiment $4(N=408)$, we replicated and extended these findings. Following random assignment to our experimental primes (terrorist threat vs. control) and our usual measure of mood, participants were then asked to express their attitudes toward a fully randomized series of 47 politically-themed statements. Some of these statements were relative to the hawkish domain, representing either prohawk (e.g., Using overwhelming military force is the best way to defeat terrorism around the world) or dovish (e.g., Diplomatic solutions to terrorism are almost always preferable to the use of military force) views. The remaining items tapped other elements of conservative or liberal ideology, including statements relevant 
to healthcare (e.g., The government has a responsibility to provide healthcare for low-income individuals) or elements of social conservatism (e.g., Abortion should be outlawed in all circumstances; Homosexual relations are morally acceptable).

After forming distinct (but correlated) indices of political attitudes via principal components analyses using promax rotation, analyses revealed two findings of interest, both of which were consistent with our model. First, analyses of a hawkish index (which included positive loadings of hawkish items and negative loadings of dovish items) revealed the same pattern of oppositional mediation seen in our previous studies: the activation of anger led to more favorable attitudes along this dimension, but sadness was responsible for more negative reactions to this same index. Second, and equally interesting, analyses revealed no effects of terrorist threat on any other aspect of ideology, after controlling for any shared variance with the hawkish index. (Conversely, analyses of the hawkish index remained significant even after controlling for these other dimensions.)

\subsubsection{Eadeh et al. (2018; Experiment 5)}

The experimental induction of anger has the potential to induce aggressive behavior and can trigger favorable appraisals of "pro-aggressive" action tendencies for the self and other people and groups (Berkowitz, 1990). In principle, this could explain why anger following terrorist threat resulted in more favorable appraisals of hawkish policies. According to our affordance model, the effects observed in the studies presented above reflect angerrelated dynamics specific to one particular type of threat (i.e., terrorism).

Fortunately, this aspect of our model — and its contrast from the alternative noted above - is easily tested. In this final study, we randomly assigned participants to one of three experimental conditions. Two of these corresponded to the threat vs. control conditions used in the preceding four studies. A third condition was designed to also induce anger, by directing participants to write about a personal "justice violating" experience that made them angry. (Importantly, analyses showed that this task triggered just as much anger as was activated following the terrorist threat prime.) After measurement of mood, all participants were asked to evaluate the Republican hawk used in Experiment 1.

If the alternative "general aggression" interpretation is correct, freshlyangered participants assigned to the personal injustice condition should be just as favorable in their reactions to the hawkish politician, compared to those primed with terrorist threat. However, we predict that anger should augment the appeal of the hawk only when this was activated in the context 
of terrorist threat. Viewed in the context of our model, this is because hawkish politicians do not offer any real "affordance" in terms of solving the problems associated with (say) unfair treatment by one's boss, or by being "cut" in line at the grocery store. This is precisely what the analyses of this study showed. More concretely, we found evidence of anger-based mediation of the Republican hawk, but only when we examined participants made angry from terrorist threat. These effects disappeared when participants were angered as a result of reminding them of a personal injustice.

This latter study looms large in the context of our affordance model. This is because it shows that the consequences of threat - and more specifically, the effects of anger on ideology - depend on the underlying reasons why participants became angry in the first place. In the discussion to follow, we consider some general theoretical issues germane to this issue, followed by the presentation of critical findings obtained by Eadeh and Chang (in press).

\subsection{Are the political effects of anger consistent for all types of threat?}

Over the course of our lifetime, we (unfortunately) are likely to come across a near-infinite number of events that could be construed as threatening. Some events are life-threatening (e.g., terrorism), and some are not. Some threats are relevant to large groups, and others are "local," posing danger only to the self. In other words, threats could include a diversity of stimuli, including "the sight of a large spider; or by the loss of their job; or by the thought of an airplane crashing; or by the prospect of being killed in a terrorist attack; or by increasing cultural diversity in their country" (Feldman, 2013, p. 55).

In his insightful commentary, Feldman (2013) goes on to make a larger point with respect to the way social and political psychologists have studied threat over the last five decades. As suggested by the preceding quote, threat is a seemingly simple word that refers to an enormously diverse class of events. To be sure, there have been some attempts to subdivide these events into smaller units, but Feldman (2013) is dubious about the value of such broad divisions:

Consider the categories "personal" and "social" threat. This distinction appears in many lines of research, [but] are personal and social threats clearly defined? In the case of terrorism, a person could be personally threatened by the fear of being killed in an attack. This could lead to an existential threat as discussed in terror management theory (Rosenblatt, Greenberg, Solomon, Pyszczynski, \& Lyon, 1989). Alternatively, that person could be concerned about the loss of family members or close 
friends. This would likely be more reflected in overt anxiety or concern for the wellbeing of others rather than the specter of one's own mortality. A person could also be personally threatened by the impending loss of a job, which is likely a very different type of threat than one that involves mortality.

Feldman (2013) makes a much-needed point about the importance for social scientists to recognize the diversity of threat. This perspective is relevant to both the design of our studies and the development of theoretical models. Although Feldman (2013) does not specifically reference the dynamics of anger, the main thrust of his argument is relevant to much of the research considered in this chapter. As we have emphasized, one reliable "trigger" of anger is the perception of injustice, with terrorism representing one example. However, it is not the only one. As we showed in Experiment 5 of Eadeh et al. (2018), anger activated in the context of terrorist threat had consequences very different from anger activated in the context of (memories of) a personal threat that had nothing to do with terrorism.

\subsection{Further evidence for context specificity: Anger-driven shifts to the political left}

Three additional studies reported by Eadeh and Chang (in press) provide even more striking evidence for the context-specific nature of anger in shaping political attitudes. Throughout this chapter, we have discussed how the Gibsonian construct of affordances could be used to explain why the activation of terrorist threat, via anger, might serve to enhance the value of one aspect of conservative values, i.e., hawkishness. In that case, the policy in question represents a perceived "fix" for the problem at hand. However, there are other threats - for which aspects of liberal ideology represent effective fixers. Here again we return to the idea of issue ownership (Seeberg, 2017), except in this case we are concerned with the possibility that certain types of threat could enhance the value of relevant aspects of liberal ideology.

A series of recent Gallup polls $(2007,2010,2017)$ and research from the American National Election Studies (ANES; Egan, 2013) show that Democrats have sizeable advantages over Republicans on how well they handle issues related to the environment, healthcare policy, discrimination against people of color, and the size and power of large corporations. Taken in isolation, these data could be interpreted as demonstrating something specific about the dynamics of American politics. However, a similar pattern is seen in other countries, not just the United States (Seeberg, 2017). Stated differently, the issue at hand goes beyond simple reputations of political parties to solve certain issues. Rather, we speak more broadly of the appeal of certain 
ideologies-here, liberalism-to effectively "deal with" certain societal problems. As a complement to our previous studies on terrorist threat, therefore, the goal of Eadeh and Chang (in press) was to show how other types of threat could enhance the value of (certain aspects of) liberalism, to the extent that these facets are seen as relevant solutions to the problem at hand.

\subsubsection{A note on the construction of our mood indices}

As before, our main interest continued to be on anger-related feelings as the predicted mediator in changes in ideological preference. Unlike our previous studies, however, this newer work accommodated a growing recognition of the overlap between anger and disgust, at least in the context of certain types of socio-moral violations (Giner-Sorolla, Kupfer, \& Sabo, 2018). In the case of the present set of studies, we found extremely high overlap between feelings of anger and disgust. (We shall discuss the larger theoretical implications of this overlap after we consider the results of this series.) For this reason, one of our composite measures (hereinafter, anger/ disgust) included a mixture of anger and disgust-related terms (mad, angry, furious, disgusted, revulsed, sickened; $\alpha=0.97$ ). In order to provide continuity with our previous studies, we also constructed a separate index of fear, based on an average of nervous, scared, afraid, fearful, anxious, worried $(\alpha=0.93)^{\text {h }}$

\subsubsection{Summary of main findings}

In Experiment $1(N=558)$, half of the participants read about the (true) story of Kyler Van Nocker, a 5-year-old stricken with an advanced stage of cancer, who was denied healthcare coverage by his parents' insurer. The other participants read an unrelated, affectively neutral story about food allergies. Following completion of a mood inventory, participants were presented with a randomized set of 50 Likert-type items probing different aspects of their political attitudes. Some items generally related to the healthcare industry, an issue which was obviously related to the content of the story about the

\footnotetext{
${ }^{\mathrm{h}}$ As for general feelings of sadness, two of the experiments reported by Eadeh and Chang (in press) involved stories about life-threatening harm to children and, in those cases, sadness was extremely highly correlated with anger/disgust. As a result, mediational analyses did not permit simultaneous entry of both indices in the same analysis due to problems of multicollinearity. However, a third experiment focused on a type of threat that did not involve harm to children and, in that case, entry of all three indices was meaningful, with no issues of multicollinearity. Most important for present purposes, inclusion of all three affect indices — anger/disgust, fear, and sadness — showed significant mediation only in the case of anger/disgust, but not fear or sadness.
} 
young child. However, other items probed entirely different aspects of political attitudes, including attitudes toward social liberalism/conservatism and a series of questions probing attitudes toward hawkish policies.

Three main findings of interest emerged from this study. First, the story about Kyler Van Nocker elicited significantly higher levels of anger/disgust compared to the control condition. Second, participants assigned to read Kyler's healthcare (vs. control) story were more likely to endorse one important aspect of contemporary pro-liberal attitudes, in the form of greater endorsement of government regulation of the healthcare industry. Third, we hypothesized and found these attitudinal changes were mediated by the anger/disgust index, but not fear. These effects are summarized in Fig. 10. Equally important, the threat manipulation exerted no reliable effects (either directly or indirectly) on any other aspect of political attitudes, including other aspects of political conservatism.

This general pattern was replicated and extended in two additional studies. In Experiment $2(N=184)$, participants were primed with a different justice violation, involving the contamination of the environment. (For example, in one version of this threat, participants read about a young child who suffered heavy metal poisoning as a result of a contaminated water supply.) In this case, analyses showed that the index of anger/disgust drove participants to express more favorable attitudes toward the EPA and other environmental policies. Experiment $3(N=225)$ demonstrated this effect in another domain, by having half of the participants read about the financial malfeasance of "big banks" in the context of the 2008 financial

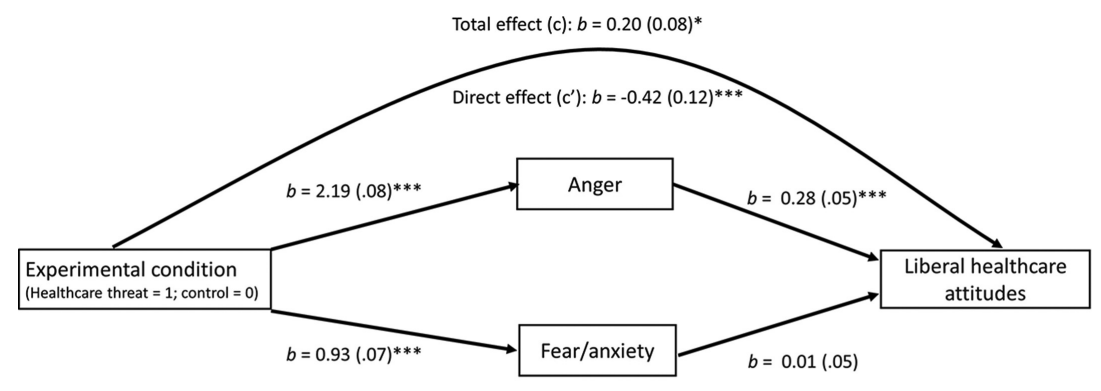

Note: Values in parentheses represent standard error estimates.

${ }^{*} p<.05 ;{ }^{* * *} p<.001$

Fig. 10 Mediational analyses on liberal healthcare attitudes: Eadeh and Chang (in press; Experiment $1 ; N=558$ ). 
crisis. Here again, activation of anger/disgust was responsible for more favorable attitudes toward a specific aspect of liberalism, in this case support for government regulation of the financial sector.

\subsubsection{Summary}

One of the larger implications of our affordance model is the need for greater specificity when considering the consequences of threat on ideology. In this context, "greater specificity" refers to two things: First, one needs to be specific as to the type of threat one is studying. Certain threats can enhance the value of attitude objects associated with conservatism, but other threats can enhance the value of liberal attitude objects. (Here we use "attitude objects" in a broad sense, to refer to issues, people, and/or groups associated with conservative or liberal values in that particular culture.)

Second, one needs to be more specific as to the type of ideological beliefs that are changing because of any given threat. Any given type of threat is likely to be relatively narrow in terms of what aspects of ideology are affected. This is where the Gibsonian notion of affordances is useful: Although ideologies are obviously more abstract than concrete entities like ladders, there are instances in which (certain aspects of) conservative or liberal ideologies might become more appealing by virtue of "affording" people's desire to achieve a certain goal. Once again, however, the potential for threat to enhance elements of conservative or liberal ideology depends on what type of threat one is considering.

\section{Part VII: On the relation of our affordance model to extant models of threat}

In previous sections, we have summarized and discussed the implications of these findings as they bear on our affordance model. In this section, we consider the broader implications of our work as it relates to relevant research in social and political psychology. To begin, we are mindful that we are hardly the first investigators to be interested in the impact of threat on ideological preferences. For example, the situational flexibility of ideology represents an idea that is central to theories of authoritarianism (e.g., Doty, Peterson, \& Winter, 1991; Feldman \& Stenner, 1997; Sales \& Friend, 1973).

The general assumption in these and other relevant areas of research is that threat elicits more approval of conservative values, even among those who ordinarily find such views distasteful. Of particular relevance is a 
comprehensive review of 55 separate studies bearing specifically on this issue. Jost, Stern, Rule, and Sterling (2017) concluded that they found "very strong support for the hypothesis that threat would be associated with "conservative shift" (p. 342). However, in the context of the issues raised by our affordance model, it is useful to re-evaluate three aspects of the conclusions reached by these investigators.

\subsection{What kinds of threat are being considered?}

Out of the 55 tests of "conservative shifts" reported by Jost et al. (2017), the vast majority-over $80 \%$ - were concerned with aggressive assaults by terrorists. The remaining samples mostly focused on xenophobic threats or the threat of physical harm from muggings or burglary. This focus is notable, as these kinds of threat are relevant to one facet of conservative ideology; namely, a "get tough" approach to dealing with norm-breakers, especially those that threaten the safety of the ingroup. As discussed earlier, different threats represent different problems with different solutions. In the case of priming terrorist threat or other aggressive affronts to the ingroup, our affordance model suggests that such threats can make this (but not other) aspects of conservatism more appealing. As we noted in the previous section, priming other types of threat can produce very different effects, including making aspects of liberalism more attractive (Eadeh \& Chang, in press).

\subsection{Are threat-driven ideological shifts relatively broad or narrow?}

Many popular measures of ideology take a "broad band" approach to assessing such beliefs, insofar as they involve the generation of a single index that collapses over several correlated but distinct aspects of ideology. This includes measures of authoritarianism, which average across items that tap appraisals of "get tough" policies (e.g., What our country really needs is a strong, determined leader who will crush evil and take us back to our true path) and conventional views about gender relations (e.g., Women should have to promise to obey their husbands when they get married). There are paradigms in which averaging across these and other aspects of conservatism can be useful, but other areas of inquiry benefit from more fine-grained (i.e., issue specific) approaches. In our view, research on the relation between threat and ideology is one of the latter areas.

As noted above, most of the studies included in the meta-analysis by Jost et al. (2017) were concerned with the threat of terrorism. Our affordance 
model suggests that any "conservative shifts" would arise most consistently for those aspects of conservatism specifically concerned with aggressive, "get tough" policies, including the kinds of hawkish orientation studied in our own research. Unfortunately, many of the reviewed studies do not permit this type of analysis, either because their primary measure used was a broadband index (e.g., authoritarianism) or operationalized ideology in other ways that did not allow full understanding of what aspects of conservatism shifted and what did not.

Nevertheless, some studies in the literature do permit a more finegrained analysis of ideological preference in the aftermath of terrorist threat. For example, consider a highly-cited study by Nail and McGregor (2009), who measured attitudes both before and after the 9/11 attacks. As these authors note, the only reliable effects of terrorist threat emerged for two items associated with pro-hawkish attitudes (George W. Bush, Increased Military Spending). In contrast, terrorist threat had no reliable impact on attitudes toward Republicans or Conservatives. Nor did terrorist threat reliably affect responses toward a variety of liberal attitude objects (American Civil Liberties Union, Liberals, Socialized Medicine, and Feminists). As noted earlier in this chapter, an analogous pattern was obtained by Lambert et al. (2010) who found (a) consistent effects of terrorist threat on ideology when these measures were concerned with aspects of hawkish policy but (b) no evidence of generalizability beyond this particular aspect of political attitudes.

To clarify, we do not make the strong claim that ideological consequences of terrorist threat never show signs of generalizing beyond "get tough" facets of conservatism. However, when such generalizability is found, one must conduct statistical analyses in order to examine the unique impact of threat on one element of conservatism, while holding other domains constant. As seen in Experiment 4, this approach is critical in order to establish whether the "shifts" in question are truly broad band, or whether they are specific to the type of threat being primed.

\subsection{What is the role of affect/emotion?}

Given the obvious relevance of threat to emotion, one might expect researchers interested in understanding the psychological consequences of threat would routinely assess the affective experience of their participants in their research design. Somewhat surprisingly, this is not the case. The aforementioned review by Jost et al. (2017) provides a case in point. 
Out of the 55 studies included in their meta-analysis, an overwhelming majority $(93 \%)$ failed to include any measure of affective experience. Of the four exceptions, three were the aforementioned studies by Lambert et al. (2010), which showed strong anger-based mediation following the 9/11 attack prime. The only other was a clinically-oriented investigation that assessed the symptoms of PTSD (Canetti-Nisim, Halperin, Sharvit, \& Hobfoll, 2009).

One can find other instances in which studies of threat do measure emotion immediately after the threat manipulation, but rely on methodologies making it difficult to use those measures in a meaningful way. For example, hundreds of studies in the terror management area fail to include an affectively neutral control group (Lambert, Eadeh, et al., 2014; Lambert, Peak, et al., 2014). This makes it impossible to assess the degree to which this threat prime produced changes in affect, and, by extension, prevents meaningful tests for affective mediation. The inclusion of affect (and a neutral control group) does not guarantee one will find evidence of affective mediation. For example, some of the consequences elicited by the mortality salience manipulation involve affect, but some do not (see Lambert, Eadeh, et al., 2014; Lambert, Peak, et al., 2014). However, our main point here is that leaving out a measure of affect entirely - a common omission in the literature on terrorist threat (Jost et al., 2017)—prevents one from determining whether there is any affective mediation in the first place.

\subsection{On the gap between theory and method}

None of the considerations raised above should be taken to imply that other models of threat (aside from our own) ignore affect as part of the theoretical principles. On the contrary, the motivated social cognition model as well as TMT places strong emphasis on emotion as part of their underlying conceptual foundation. However, when one closely examines the methodologies used in those research programs (and the way affect is operationalized), one can often find a curious gap. In particular, the theoretical principles of these models suggest that affect may be integral, but the methodologies of their studies do not always reflect this emphasis.

In the case of the motivated social cognition model, we have noted the near-complete absence of measures of mood/emotion among the studies that are approvingly cited as supporting the predicted "conservative shift" following the activation of threat (Jost et al., 2017). Again, this does not mean that the model presented by Jost et al. (2017) predicts that affect plays 
no role in such shifts. A more accurate characterization is that these studies are silent on this possibility: they are not able to say whether affect plays a mediating role or not. Data can answer this question, but if there are no data, the question remains unanswered. A similar problem pervades TMT, but for a different reason. Here, many studies do measure affect, but the absence of a neutral control group means that the question of affective mediation remains unanswered.

A distinct but related problem pertains to an issue we discussed earlier in this chapter, namely, the widespread use of "broad-band" measures of affect, as reflected by ubiquitous reliance on the 10-item indices of positive and negative affect from either the original or revised version of the PANAS (Watson et al., 1988) There are research contexts in which a broad-band approach to measuring affect can be useful but_as in the case of assessing ideology - there are instances in which a more fine-grained analysis is needed. Such is the case for research on the consequences of threat, in which specificity is needed for both the measurement of affect and ideology.

\section{Part VIII: Anger vs. disgust: How and when are they distinct?}

Throughout the various programs of research discussed in this chapter, our own work was primarily focused on anger and its distinction from fear and sadness. As noted in a previous section, however, our work has started to consider the dynamics of disgust. Here, we discuss some interesting and important issues that have emerged from our laboratory, particularly as they bear on the similarities and differences between this emotion and anger. In the context of this discussion, we draw on a recent review by Giner-Sorolla et al. (2018), as well as important advances in the field of morality and emotion (e.g., Hutcherson \& Gross, 2011; Rozin, Lowery, Imada, \& Haidt, 1999; Schein \& Gray, 2018; Wisneski \& Skitka, 2017).

As any student of introductory psychology can tell you (assuming they have been paying attention), facial displays of anger vs. disgust are distinguishable from each other within and across cultures (Ekman, 1999; Ekman \& Friesen, 1971; but see also Gendron, Roberson, van der Vyver, \& Barrett, 2014). Moreover, from the layperson's perspective, the physical sensations of these two emotions appear to be somewhat different. For example, the common English phrase "this makes my blood boil" clearly refers to anger, but "this makes me feel sick to my stomach" is far more aligned with disgust 
(Giner-Sorolla et al., 2018). In short, the average layperson is likely to affirm that anger and disgust are distinct feelings.

More recent research on morality and emotion also confirms the distinction between these two emotions, but there is a catch: it depends on what type of disgust you are talking about. One aspect of disgust refers to bodily-moral violations (Giner-Sorolla et al., 2018), a concept that shares some overlap with what are sometimes called violations of divinity/purity (Shweder, Much, Mahapatra, \& Park, 1997; see also Rozin et al., 1999). These violations refer to instances in which "a person does something that directly violates a moralized rule about how the body is used" (GinerSorolla et al., 2018, p. 235), which would include violations of sexual taboos (e.g., incest) or other perceived "infractions" involving purity (see also Chakroff, Dungan, \& Young, 2013; Rottman, Kelemen, \& Young, 2014). In these and other scenarios, people's emotional reactions tend to be dominated by disgust compared to anger.

The distinction between these two emotions becomes much less clear when one considers socio-moral violations, in which "a person does something that can be judged according to rules about helping or hurting someone" (Giner-Sorolla et al., 2018, p. 235; emphasis added). Here we enter a much broader realm of norm-breaking behavior, including virtually any type of justice violation. To be sure, some socio-moral violations evoke relatively more disgust than anger, and vice versa. However, the general pattern emerging from the literature is that such violations tend to trigger anger and disgust simultaneously. For example, violations of civil rights (or violations of individual freedom) tend to evoke strong anger, but these feelings are accompanied by feelings of disgust as well (e.g., Rozin et al., 1999). However, it is important to note that in the realm of socio-moral violations, there is some disagreement among scholars in terms of the exact antecedents of anger vs. disgust and the conditions under which one emotion will take priority over another. For example, the social-functionalist model of Hutcherson and Gross (2011) offers predictions that are, in some ways, distinct from those offered by the "CAD" (contempt-anger-disgust) framework offered by Rozin et al. (1999).

\subsection{Two illustrative findings from our own work}

The challenges in separating anger from disgust can be seen from our own studies. One of these is relevant to a study we already discussed in a previous section, that by Eadeh and Chang (in press). In this study, participants read 
about an insurance company that denied coverage to a child suffering from a rare form of cancer. Preliminary analyses revealed an extremely high overlap between feelings of anger and disgust, and, for this reason, Eadeh and Chang (in press) constructed a composite index combining anger-related and disgust-related items (angry vs. disgusted, respectively).

Another way of illustrating this overlap is to construct two separate indices, one focusing on feelings of anger (averaging across angry, mad, irate, and furious; $\alpha=0.97$ ) and another focusing on feelings of disgust (averaging across disgusted, revulsion, repulsed, nauseated, and sickened; $\alpha=0.95)$. The correlation between these two composites was an eye-popping 0.93 . The magnitude of this correlation is obviously high enough to conclude that, at least in this particular case, these two measures were assessing the same underlying construct.

Another illustration of the overlap between anger and disgust emerged in the context of an even newer line of research from our laboratory, which concerns the factors that motivate people to participate vs. abstain from voting (Lambert, Cunningham, Eadeh, \& Hanson, 2018). In one study, we conducted an anonymous survey of several hundred American adults a few weeks prior to the 2018 midterm elections, with an interest in understanding the affective dynamics that predict whether these participants reported relatively high or low inclinations to vote in local and statewide elections. This sample slightly skewed to the political left, but our final sample contained a respectable balance of self-identified Democrats $(N=177)$, Independents $(N=101)$, and Republicans $(N=105)$.

In one part of the survey, we assessed participants' feelings toward a number of "partisan" attitude objects (e.g., Republicans, Democrats, Donald Trump, Hillary Clinton), counterbalanced for order. More specifically, participants expressed their feelings toward each target with respect to eight emotions (presented in a different randomized order for each participant), four of which were positive (happiness, hope, inspiration, pride) and four of which were negative (anger, disgust, fear, and sadness). Following this, all participants completed a block of items asking them for their self-reported intention to vote (e.g., "What is the likelihood that you will vote in the upcoming elections in November?").

It is worth noting that any feelings of negativity toward these groups/ people were highly likely to involve socio-moral violations (e.g., involving the perception of lying to the American people). This point is important because, in this study, as in the case of Eadeh and Chang (in press), anger and disgust were highly correlated (here, above 0.80). Of greater interest, 
both of these emotions were positive predictors of voting intentions: Higher levels of anger and higher levels of disgust were excellent predictors of relatively high intentions to vote, with correlations in the $0.40-0.50$ range. This was equally true of Democrats and Republicans and, to a lesser extent, Independents. In contrast, feelings of sadness and fear were far less predictive of intentions to vote, although they were in the same direction.

In this study, as well as the aforementioned investigation by Eadeh and Chang (in press), the overlap between anger and disgust was too great to attempt any meaningful "teasing apart" of their unique variance. Nevertheless, use of other methodological tools to assess affect, such as asking participants to express their internal sensations (e.g., "feeling their blood boil" vs. "feeling nauseated") or asking them to select facial expressions that best match their feelings, may provide better opportunities for separation of anger and disgust as distinct affective states (for a related discussion, see Giner-Sorolla et al., 2018). These approaches may be useful in determining whether anger and disgust play equal roles in determining individuals' level of involvement in politics, including but not limited to their intention to vote.

One last issue regarding the anger-disgust relationship is worth noting. As we have discussed in this chapter, recent work in social-neuroscience has strongly confirmed that anger is an approach emotion (Carver \& Harmon-Jones, 2009). Given the overlap between anger and disgust (at least in the context of socio-moral violations), this raises an important question: Are there circumstances under which disgust, too, might serve to activate the approach centers of the brain? Importantly, our focus here is on the type of disgust that is triggered by perceptions of unjust acts, not the feelings that are elicited by bodily-purity violations. As of this writing, however, this question awaits empirical resolution, as there are no studies in the social neuroscience area that have specifically focused on anger and this type of disgust in the service of tracking their relevance to the approach vs. avoidance centers in the brain (Harmon-Jones, 2018, personal communication).

\subsection{CODA}

In writing this chapter, our goal was to convey exciting developments in the fields of social and political psychology pertaining to the role of anger. One of the central messages of our work is that anger plays an important role in motivating people to rectify injustices, a quality that is distinct from other negative emotions (with the caveat that this sometimes overlaps with 
socio-moral facets of disgust; see above). Anger is the opposite of apathy. If people never got angry, our society would look very different from the way it is now: No protests, no social movements to effect change, and no fights to protect the rights of others. This perspective in no way absolves anger of its darker side. Anger is clearly responsible for many evils, including but not limited to reprehensible acts of violence against people and groups. However, an important goal of future research on anger should be to understand how to channel this emotion in a way that creates positive change and results in a more fair and just society.

\section{References}

Abe, J. A. A. (2011). Positive emotions, emotional intelligence, and successful experiential learning. Personality and Individual Differences, 51, 817-822.

Alker, H. A., \& Poppen, P. J. (1973). Personality and ideology in university students. Journal of Personality, 41, 653-671.

Allport, G. W. (1937). Personality: A psychological interpretation. Oxford, England: Holt.

Altemeyer, B. (1988). Enemies of freedom: Understanding right-wing authoritarianism. Jossey-Bass.

Anderson, C. A. (2001). Heat and violence. Current Directions in Psychological Science, 10, 33-38.

Aquino, K., Tripp, T. M., \& Bies, R. J. (2001). How employees respond to personal offense: The effects of blame attribution, victim status, and offender status on revenge and reconciliation in the workplace. Journal of Applied Psychology, 86, 52-59.

Axelrod, R., \& Hamilton, W. D. (1981). The evolution of cooperation. Science, 211, 1390-1396.

Baker, W. D., \& O’Neal, J. R. (2001). Patriotism or opinion leadership? The nature and origins of the "rally 'round the flag" effect. Journal of Conflict Resolution, 45, 661-687.

Barber, L., Maltby, J., \& Macaskill, A. (2005). Angry memories and thoughts of revenge: The relationship between forgiveness and anger rumination. Personality and Individual Differences, 39, 253-262.

Baron, R. M., \& Kenny, D. A. (1986). The moderator-mediator variable distinction in social psychological research: Conceptual, strategic, and statistical considerations. Journal of Personality and Social Psychology, 51, 1173-1182.

Batson, C. D., Kennedy, C. L., Nord, L. A., Stocks, E. L., Fleming, D. Y. A., Marzette, C. M., ... Zerger, T. (2007). Anger at unfairness: Is it moral outrage? European Journal of Social Psychology, 37, 1272-1285.

Beer, J. S. (2017). Current emotion research in social neuroscience: How does emotion influence social cognition? Emotion Review, 9, 172-180.

Bem, D. J. (1972). Self-perception theory. In L. Berkowitz (Ed.), Vol. 6. Advances in experimental social psychology (pp. 1-62). New York: Academic Press.

Bennett, M., \& Earwaker, D. (1994). Victims' responses to apologies: The effects of offender responsibility and offense severity. The Journal of Social Psychology, 134, 457-464.

Berkowitz, L. (1990). On the formation and regulation of anger and aggression: A cognitiveneoassociationistic analysis. American Psychologist, 45, 494-503.

Berridge, K. C. (2003). Pleasures of the brain. Brain and Cognition, 52, 106-128.

Bies, R. J., \& Tripp, T. M. (1995). The use and abuse of power: Justice as social control. In R. Cropanzano \& M. Kacmar (Eds.), Politics, justice, and support: Managing social climate at work (pp. 131-146). Westport, CT: Quorum Press.

Blackhart, G. C., Nelson, B. C., Knowles, M. L., \& Baumeister, R. F. (2009). Rejection elicits emotional reactions but neither causes immediate distress nor lowers self-esteem: 
A meta-analytic review of 192 studies on social exclusion. Personality and Social Psychology Review, 13, 269-309.

Bobocel, D. R., Kay, A. C., Zanna, M. P., \& Olson, J. M. (Eds.), (2011). The Psychology of Justice and Legitimacy. Taylor \& Francis.

Bodenhausen, G. V., Sheppard, L. A., \& Kramer, G. P. (1994). Negative affect and social judgment: The differential impact of anger and sadness. European Journal of Social Psychology, 24, 45-62.

Bond, A. J., \& Wingrove, J. (2010). The neurochemistry and psychopharmacology of anger. In M. Potegal, G. Stemmler, \& C. Spielberger (Eds.), International handbook of anger (pp. 79-102). New York, NY: Springer.

Boon, S. D., Deveau, V. L., \& Alibhai, A. M. (2009). Payback: The parameters of revenge in romantic relationships. Journal of Social and Personal Relationships, 26, 747-768.

Bradfield, M., \& Aquino, K. (1999). The effects of blame attributions and offender likableness on forgiveness and revenge in the workplace. Journal of Management, 25, 607-631.

Brewer, M. B. (1999). The psychology of prejudice: Ingroup love and outgroup hate? Journal of Social Issues, 55, 429-444.

Brown, J. L. (1964). The evolution of diversity in avian territorial systems. The Wilson Bulletin, 76, 160-169.

Bushman, B. J. (2002). Does venting anger feed or extinguish the flame? Catharsis, rumination, distraction, anger, and aggressive responding. Personality and Social Psychology Bulletin, 28, 724-731.

Callan, M. J., Sutton, R. M., Harvey, A. J., \& Dawtry, R. J. (2014). Immanent justice reasoning: Theory, research, and current directions. In Vol. 49. Advances in experimental social psychology (pp. 105-161). Academic Press.

Canetti-Nisim, D., Halperin, E., Sharvit, K., \& Hobfoll, S. E. (2009). A new stress-based model of political extremism: Personal exposure to terrorism, psychological distress, and exclusionist political attitudes. Journal of Conflict Resolution, 53, 363-389.

Carlsmith, K. M., \& Darley, J. M. (2008). Psychological aspects of retributive justice. Advances in Experimental Social Psychology, 40, 193-236.

Carlsmith, K. M., Wilson, T. D., \& Gilbert, D. T. (2008). The paradoxical consequences of revenge. Journal of Personality and Social Psychology, 95, 1316-1324.

Carroll, J. S., Perkowitz, W. T., Lurigio, A. J., \& Weaver, F. M. (1987). Sentencing goals, causal attributions, ideology, and personality. Journal of Personality and Social Psychology, 52, 107-118.

Carver, C. S., \& Harmon-Jones, E. (2009). Anger is an approach-related affect: Evidence and implications. Psychological Bulletin, 135, 183-204.

Cattell, R. B. (1957). Personality and motivation structure and measurement. Oxford, England: World Book Co.

Chakroff, A., Dungan, J., \& Young, L. (2013). Harming ourselves and defiling others: What determines a moral domain? PLoS One, 8(9), e74434.

Chester, D. S., \& DeWall, C. N. (2015). The pleasure of revenge: Retaliatory aggression arises from a neural imbalance toward reward. Social Cognitive and Affective Neuroscience, 11, 1173-1182.

Chester, D. S., \& DeWall, C. N. (2017). Combating the sting of rejection with the pleasure of revenge: A new look at how emotion shapes aggression. Journal of Personality and Social Psychology, 112, 413-430.

Clore, G. L. (1994). Why emotions are felt. In P. Ekman \& R. J. Davidson (Eds.), The nature of emotion (pp. 103-111). New York: Oxford University Press.

Costa, P. T., Jr., \& McCrae, R. R. (1995). Domains and facets: Hierarchical personality assessment using the revised NEO personality inventory. Journal of Personality Assessment, 64, 21-50.

Costa, P. T., \& McCrae, R. R. (1985). Manual for the NEO personality inventory. (pp. 323-339). Odessa, FL: Psychological Assessment Resources. 
Cottrell, C. A., \& Neuberg, S. L. (2005). Different emotional reactions to different groups: A sociofunctional threat-based approach to "prejudice" Journal of Personality and Social Psychology, 88, 770-789.

Crawford, J. R., \& Henry, J. D. (2004). The positive and negative affect schedule (PANAS): Construct validity, measurement properties and normative data in a large non-clinical sample. British Journal of Clinical Psychology, 43, 245-265.

Daly, M., \& Wilson, M. (1988). Evolutionary social psychology and family homicide. Science, 242, 519-524.

Darby, B. W., \& Schlenker, B. R. (1982). Children's reactions to apologies. Journal of Personality and Social Psychology, 43, 742-753.

Darley, J. M., \& Pittman, T. S. (2003). The psychology of compensatory and retributive justice. Personality and Social Psychology Review, 7(4), 324-336.

Darwin, C. (1872). The expression of the emotions in man and animals. London: Murray.

de Quervain, D. J.-F., Fischbacher, U., Treyer, V., Schellhammer, M., Schnyder, U., Buck, A., et al. (2004). The neural basis of altruistic punishment. Science, 305, 1254-1258.

Doty, R. M., Peterson, B. E., \& Winter, D. G. (1991). Threat and authoritarianism in the United States, 1978-1987. Journal of Personality and Social Psychology, 61, 629-640.

Dutton, D. G. (2010). Anger in intimate relationships. In M. Potegal, G. Stemmler, \& C. Spielberger (Eds.), International handbook of anger (pp. 535-544). New York, NY: Springer.

Eadeh, F. R. (2017). Healthcare vs. hawkishness: The divergent effects of affect on context-driven shifts in attitudes. Unpublished doctoral dissertation. St. Louis, Missouri, USA: Washington University.

Eadeh F.R. and Chang K.K., (in press). Can threat increase support for liberalism? New insights into the relationship between threat and political attitudes, Social Psychological and Personality Science.

Eadeh, F. R., Dorison, C., Hanson, E. J., Peak, S. A., Slochower, J., Skallerud, W. K., \& Lambert, A. J. (2018). Towards a greater understanding of the consequences of terrorism for political attitudes: A "threat-affordance" framework. Unpublished Manuscript.

Eadeh, F. R., Peak, S. A., \& Lambert, A. J. (2017). The bittersweet taste of revenge: On the negative and positive consequences of retaliation. Journal of Experimental Social Psychology, 68, 27-39.

Egan, P. (2013). Partisan priorities: How issue ownership drives and distorts American politics. New York, NY: Cambridge University Press.

Ekkekakis, P. (2013). The measurement of affect, mood, and emotion: A guide for health-behavioral research. Cambridge University Press.

Ekman, P. (1999). Basic emotions. In T. Dalgleish \& M. Power (Eds.), Handbook of cognition and emotion (pp. 45-60). Chichester: John Wiley and Sons Co.

Ekman, P., \& Friesen, W. V. (1971). Constants across cultures in the face and emotion. Journal of Personality and Social Psychology, 17(2), 124.

Ekman, P., Levenson, R. W., \& Friesen, W. V. (1983). Autonomic nervous system activity distinguishes among emotions. Science, 221, 1208-1210.

Ekman, P., \& Rosenberg, E. L. (Eds.), (1997). What the face reveals: Basic and applied studies of spontaneous expression using the facial action coding system (FACS). USA: Oxford University Press.

Eysenck, H. J. (1952). Schizothymia-cyclothymia as a dimension of personality: II. Experimental 1. Journal of Personality, 20, 345-384.

Fehr, E., \& Gächter, S. (2002). Altruistic punishment in humans. Nature, 415, 137-140.

Feldman, S. (2013). Comments on: Authoritarianism in social context: The role of threat. International Journal of Psychology, 48, 55-59.

Feldman, S., \& Stenner, K. (1997). Perceived threat and authoritarianism. Political Psychology, 18(4), 741-770. 
Forgas, J. P. (1995). Mood and judgment: The affect infusion model (AIM). Psychological Bulletin, 117, 39-66.

Fredrickson, B. L., \& Branigan, C. (2005). Positive emotions broaden the scope of attention and thought-action repertoires. Cognition \& Emotion, 19, 313-332.

Frijda, N. H. (1986). The emotions. Cambridge University Press.

Frijda, N. H. (1988). The laws of emotion. American Psychologist, 43, 349-358.

Frijda, N. H., \& Mesquita, B. (1994). The social roles and functions of emotions. In S. Kitayama \& H. R. Markus (Eds.), Emotion and culture: Empirical studies of mutual influence (pp. 51-87). Washington, DC: American Psychological Association.

Funk, F., McGeer, V., \& Gollwitzer, M. (2014). Get the message: Punishment is satisfying if the transgressor responds to its communicative intent. Personality and Social Psychology Bulletin, 40, 986-997.

Gardner, H. (1983). Frames of minds: The history of multiple intelligences. Basic Books.

Gendron, M., Roberson, D., van der Vyver, J. M., \& Barrett, L. F. (2014). Perceptions of emotion from facial expressions are not culturally universal: Evidence from a remote culture. Emotion, 14(2), 251.

Gibson, J. J. (1977). The theory of affordances. In R. Shaw \& J. Bransford (Eds.), Perceiving, acting, and knowing: Toward an ecological psychology (pp. 67-82). Hillsdale, NJ: Erlbaum.

Gibson, J. J. (1979). The ecological approach to visual perception. Boston: Houghton Mifflin.

Giner-Sorolla, R. (1999). Affect in attitude. Immediate and deliberative perspectives. In S. Chaiken \& Y. Trope (Eds.), Dual process theories in social psychology (pp. 441-461). New York: Guilford.

Giner-Sorolla, R., Kupfer, T., \& Sabo, J. (2018). What makes moral disgust special? An integrative functional review. In Vol. 57. Advances in experimental social psychology (pp. 223-289). Academic Press.

Goldstein, M. D., \& Strube, M. J. (1994). Independence revisited: The relation between positive and negative affect in a naturalistic setting. Personality and Social Psychology Bulletin, 20, 57-64.

Gollwitzer, M. (2009). Justice and revenge. In M. E. Oswald, S. Bieneck, \& J. HupfeldHeinemann (Eds.), Social psychology of punishment of crime (pp. 137-156). Hoboken, NJ: Wiley.

Gollwitzer, M., Meder, M., \& Schmitt, M. (2011). What gives victims satisfaction when they seek revenge? European Journal of Social Psychology, 41, 364-374.

Green, D. P., Salovey, P., \& Truax, K. M. (1999). Static, dynamic, and causative bipolarity of affect. Journal of Personality and Social Psychology, 76, 856-867.

Greeno, J. G. (1994). Gibson's affordances. Psychological Review, 101(2), 336-342.

Grégoire, Y., Laufer, D., \& Tripp, T. M. (2010). A comprehensive model of customer direct and indirect revenge: Understanding the effects of perceived greed and customer power. Journal of the Academy of Marketing Science, 38, 738-758.

Hafer, C. L., \& Olson, J. M. (2003). An analysis of empirical research on the scope of justice. Personality and Social Psychology Review, 7, 311-323.

Hafer, C. L., \& Rubel, A. N. (2015). The why and how of defending belief in a just world. In Vol. 51. Advances in experimental social psychology (pp. 41-96). Academic Press.

Halperin, E., Russell, A. G., Dweck, C. S., \& Gross, J. J. (2011). Anger, hatred, and the quest for peace: Anger can be constructive in the absence of hatred. Journal of Conflict Resolution, 55(2), 274-291.

Harmon-Jones, E., \& Allen, J. J. (1998). Anger and frontal brain activity: EEG asymmetry consistent with approach motivation despite negative affective valence. Journal of Personality and Social Psychology, 74, 1310-1316.

Harmon-Jones, C., Bastian, B., \& Harmon-Jones, E. (2016). Detecting transient emotional responses with improved self-report measures and instructions. Emotion, 16, 1086-1096. 
Harmon-Jones, E., Gable, P. A., \& Peterson, C. K. (2010). The role of asymmetric frontal cortical activity in emotion-related phenomena: A review and update. Biological Psychology, 84, 451-462.

Harmon-Jones, E., Harmon-Jones, C., Abramson, L., \& Peterson, C. K. (2009). PANAS positive activation is associated with anger. Emotion, 9, 183-196.

Harmon-Jones, E., Price, T. F., Gable, P. A., \& Peterson, C. K. (2014). Approach motivation and its relationship to positive and negative emotions. In M. M. Tugade, M. N. Shiota, \& L. D. Kirby (Eds.), Handbook of positive emotions (pp. 103-118). New York, NY: Guilford Press.

Hayes, A. F. (2013). Introduction to mediation, moderation, and conditional process analysis: A regression-based approach. New York: The Guilford Press.

Hertel, G., \& Kerr, N. L. (2001). Priming in-group favoritism: The impact of normative scripts in the minimal group paradigm. Journal of Experimental Social Psychology, 37, 316-324.

Hess, U., \& Thibault, P. (2009). Darwin and emotion expression. American Psychologist, 64, $120-128$.

Hetherington, M. J., \& Nelson, M. (2003). Anatomy of a rally effect: George W. Bush and the war on terrorism. PS: Political Science \& Politics, 36, 37-42.

Hogan, R., \& Emler, N. P. (1981). Retributive justice. In M. J. Lerner \& S. C. Lerner (Eds.), The justice motive in social behavior (pp. 125-144). New York: Academic Press.

Hopfensitz, A., \& Reuben, E. (2009). The importance of emotions for the effectiveness of social punishment. The Economic Journal, 119, 1534-1559.

Hortensius, R., Schutter, D. J., \& Harmon-Jones, E. (2011). When anger leads to aggression: Induction of relative left frontal cortical activity with transcranial direct current stimulation increases the anger-aggression relationship. Social Cognitive and Affective Neuroscience, 7, 342-347.

Huddy, L., Feldman, S., \& Cassese, E. (2007). On the distinct political effects of anxiety and anger. In W. R. Neuman, G. E. Marcus, M. Mackuen, \& A. Crigler (Eds.), The affect effect: Dynamics of emotion in political thinking and behavior (pp. 202-230).

Huntsinger, J. R., Isbell, L. M., \& Clore, G. L. (2014). The affective control of thought: Malleable, not fixed. Psychological Review, 121, 600-618.

Hutcherson, C. A., \& Gross, J. J. (2011). The moral emotions: A social-functionalist account of anger, disgust, and contempt. Journal of Personality and Social Psychology, 100(4), 719.

Janoff-Bulman, R. (2009). To provide or protect: Motivational bases of political liberalism and conservatism. Psychological Inquiry, 20, 120-128.

Johnson, E. J., \& Tversky, A. (1983). Affect, generalization, and the perception of risk. Journal of Personality and Social Psychology, 45, 20-31.

Jost, J. T., Stern, C., Rule, N. O., \& Sterling, J. (2017). The politics of fear: Is there an ideological asymmetry in existential motivation? Social Cognition, 35, 324-353.

Kahn, J. H., Tobin, R. M., Massey, A. E., \& Anderson, J. A. (2007). Measuring emotional expression with the linguistic inquiry and word count. The American Journal of Psychology, 120, 263-286.

Kahneman, D., Slovic, P., \& Tversky, A. (1982). Judgment under uncertainty: Heuristics and biases. Cambridge University Press.

Keltner, D., Locke, K. D., \& Aurain, P. C. (1993). The influence of attributions on the relevance of negative feelings to personal satisfaction. Personality and Social Psychology Bulletin, 19, 21-29.

Kenny, D. A. (2017). Mediation. Retrieved from www.DavidKenny.Net/Cm/mediate.html.

Knight, K. (1999). Liberalism and conservatism. In J. P. Robinson, P. R. Shaver, \& L. S. Wrightsman (Eds.), Measures of social psychological attitudes (pp. 59-158). San Diego, CA: Academic Press.

Knutson, B. (2004). Sweet revenge? Science, 305, 1246-1247. 
Konečni, V. J. (1974). Self-arousal, dissipation of anger, and aggression. Personality and Social Psychology Bulletin, 1(1), 192-194.

Lambert, A. J., Cunningham, G., Eadeh, F. R., \& Hanson, E. J. (2018). On the role of anger and disgust in predicting intentions to vote in the 2018 midterms. Unpublished raw data.

Lambert, A. J., Eadeh, F. R., Peak, S. A., Scherer, L. D., Schott, J. P., \& Slochower, J. M. (2014). Toward a greater understanding of the emotional dynamics of the mortality salience manipulation: Revisiting the "affect-free" claim of terror management research. Journal of Personality and Social Psychology, 106, 655-678.

Lambert, A. J., Khan, S. R., Lickel, B. A., \& Fricke, K. (1997). Mood and the correction of positive versus negative stereotypes. Journal of Personality and Social Psychology, 72, 1002-1016.

Lambert, A. J., Peak, S. A., Eadeh, F. R., \& Schott, J. P. (2014). How do you feel now? On the perceptual distortion of extremely recent changes in anger. Journal of Experimental Social Psychology, 52, 82-95.

Lambert, A. J., \& Scherer, L. D. (2013). Measurement and methodology in social cognition: An historical perspective. In D. Carlston (Ed.), Oxford Handbook of Social Cognition. Oxford University Press.

Lambert, A. J., Scherer, L. D., Schott, J. P., Olson, K. R., Andrews, R. K., O’brien, T. C., \& Zisser, A. R. (2010). Rally effects, threat, and attitude change: An integrative approach to understanding the role of emotion. Journal of Personality and Social Psychology, 98, 886-903.

LeDoux, J. E. (1994). Emotion, memory and the brain. Scientific American, 270, 50-57.

LeDoux, J. (1996). The emotional brain: The mysterious underpinnings of emotional life. Simon and Schuster.

Lerner, M. J. (1980). The belief in a just world: A fundamental delusion. New York: Plenum Press.

Lerner, J. S., Gonzalez, R. M., Small, D. A., \& Fischhoff, B. (2003). Effects of fear and anger on perceived risks of terrorism: A national field experiment. Psychological Science, 14, 144-150.

Lerner, J. S., \& Keltner, D. (2000). Beyond valence: Toward a model of emotion-specific influences on judgement and choice. Cognition E Emotion, 14, 473-493.

Lerner, J. S., \& Keltner, D. (2001). Fear, anger, and risk. Journal of Personality and Social Psychology, 81, 146-159.

Lerner, J. S., Li, Y., Valdesolo, P., \& Kassam, K. S. (2015). Emotion and decision making. Annual Review of Psychology, 66, 799-823.

Lickel, B., Miller, N., Stenstrom, D. M., Denson, T. F., \& Schmader, T. (2006). Vicarious retribution: The role of collective blame in intergroup aggression. Personality and Social Psychology Review, 10, 372-390.

Litvak, P. M., Lerner, J. S., Tiedens, L. Z., \& Shonk, K. (2010). Fuel in the fire: How anger impacts judgment and decision-making. In M. Potegal, G. Stemmler, \& C. Spielberger (Eds.), International handbook of anger (pp. 287-310). New York, NY: Springer.

Loewenstein, G. F., Weber, E. U., Hsee, C. K., \& Welch, N. (2001). Risk as feelings. Psychological Bulletin, 127(2), 267-286.

McClelland, R. T. (2010). The pleasures of revenge. Journal of Mind and Behavior, 31, 195-235.

Miller, D., \& Vidmar, N. (1981). The social psychology of punishment reactions. In S. Lerner \& M. Lerner (Eds.), The justice motive in social behavior (pp. 145-167). New York: Plenum Press.

Mishra, P. (2017). Age of anger: A history of the present. Macmillan.

Mueller, J. E. (1970). Presidential popularity from Truman to Johnson. American Political Science Review, 64, 18-34.

Nail, P. R., \& McGregor, I. (2009). Conservative shift among liberals and conservatives following 9/11/01. Social Justice Research, 22, 231-240. 
Neisser, U., Boodoo, G., Bouchard, T. J., Jr., Boykin, A. W., Brody, N., Ceci, S. J., ... Urbina, S. (1996). Intelligence: Knowns and unknowns. American Psychologist, 51, 77-101.

Nesse, R. M., \& Williams, G. C. (1996). Why we get sick: The new science of Darwinian medicine. Vintage.

Newport, F. (2014). Republicans expand edge as better party against terrorism. September 11. Retrieved from https://news.gallup.com/poll/175727/republicans-expand-edgebetter-party-against-terrorism.aspx.

Norman, D. A. (1999). Affordance, conventions, and design. Interactions, 6(3), 38-42.

Nunnally, J. C. (1978). Psychometric theory (2nd ed.). New York: McGraw-Hill.

Osgood, J. M. (2017). Is revenge about retributive justice, deterring harm, or both? Social and Personality Psychology Compass, 11, e12296.

Pennebaker, J. W., Booth, R. J., Boyd, R. L., \& Francis, M. E. (2015). Linguistic inquiry and word count: LIWC2015. Austin, TX: Pennebaker Conglomerates.

Petrocik, J. R. (1996). Issue ownership in presidential elections, with a 1980 case study. American Journal of Political Science, 40, 825-850.

Quigley, B. M., \& Tedeschi, J. T. (1996). Mediating effects of blame attributions on feelings of anger. Personality and Social Psychology Bulletin, 22, 1280-1288.

Raghunathan, R., \& Pham, M. T. (1999). All negative moods are not equal: Motivational influences of anxiety and sadness on decision making. Organizational Behavior and Human Decision Processes, 79, 56-77.

Reifen-Tagar, M., Morgan, G. S., Halperin, E., \& Skitka, L. J. (2014). When ideology matters: Moral conviction and the association between ideology and policy preferences in the Israeli-Palestinian conflict. European Journal of Social Psychology, 44(2), 117-125.

Reifin-Tagar, M., Frederico, C. M., \& Halperin, E. (2011). The positive effect of negative emotions in protracted conflict: The case of anger. Journal of Experimental Social Psychology, 47, 157-163.

Roese, N. J., \& Sherman, J. W. (2007). Expectancy. In A. W. Kruglanski \& E. T. Higgins (Eds.), Handbook of social psychology: Basic principles (2nd ed., pp. 91-115). New York: Guilford.

Ross, M., \& Miller, D. T. (2002). The justice motive in everyday life. Cambridge University Press.

Rottman, J., Kelemen, D., \& Young, L. (2014). Tainting the soul: Purity concerns predict moral judgments of suicide. Cognition, 130(2), 217-226.

Rozin, P., Lowery, L., Imada, S., \& Haidt, J. (1999). The CAD triad hypothesis: A mapping between three moral emotions (contempt, anger, disgust) and three moral codes (community, autonomy, divinity). Journal of Personality and Social Psychology, 76(4), 574-586.

Russell, J. A. (2003). Core affect and the psychological construction of emotion. Psychological Review, 110, 145-172.

Russell, J. A., \& Barrett, L. F. (1999). Core affect, prototypical emotional episodes, and other things called emotion: dissecting the elephant. Journal of Personality and Social Psychology, 76, 805-819.

Russell, J. A., \& Carroll, J. M. (1999). On the bipolarity of positive and negative affect. Psychological Bulletin, 125, 3-30.

Rusting, C. L., \& Nolen-Hoeksema, S. (1998). Regulating responses to anger: Effects of rumination and distraction on angry mood. Journal of Personality and Social Psychology, 74, 790-803.

Sadler, M. S., Lineberger, M., Correll, J., \& Park, B. (2005). Emotions, attributions, and policy endorsement in response to the September 11 th terrorist attacks. Basic and Applied Social Psychology, 27, 249-258.

Salancik, G. R., \& Conway, M. (1975). Attitude inferences from salient and relevant cognitive content about behavior. Journal of Personality and Social Psychology, 32, 829-840. 
Sales, S. M., \& Friend, K. E. (1973). Success and failure as determinants of level of authoritarianism. Behavioral Science, 18, 163-172.

Schein, C., \& Gray, K. (2018). The theory of dyadic morality: Reinventing moral judgment by redefining harm. Personality and Social Psychology Review, 22(1), 32-70.

Schimel, J., Simon, L., Greenberg, J., Pyszczynski, T., Solomon, S., Waxmonsky, J., \& Arndt, J. (1999). Stereotypes and terror management: Evidence that mortality salience enhances stereotypic thinking and preferences. Journal of Personality and Social Psychology, 77, 905-926.

Schwarz, N. (1990). Feelings as information: Informational and motivational functions of affective states. In E. T. Higgins \& R. M. Sorrentino (Eds.), Handbook of motivation and cognition: Foundations of social behaviour, Vol. 2. (pp. 527-561). New York: Guilford Press.

Schwarz, N. (2012). Feelings-as-information theory. In P. A. M. Van Lange, A. Kruglanski, \& E. T. Higgins (Eds.), Handbook of theories of social psychology (pp. 289-308). Thousand Oaks, CA: Sage.

Schwarz, N., \& Clore, G. L. (2007). Feelings and phenomenal experiences. In A. Kruglanski \& E. T. Higgins (Eds.), Social psychology. Handbook of basic principles (2nd ed., pp. 385-407). New York: Guilford.

Seeberg, H. B. (2017). How stable is political parties' issue ownership? A cross-time, crossnational analysis. Political Studies, 65, 475-492.

Seip, E. C., Van Dijk, W. W., \& Rotteveel, M. (2014). Anger motivates costly punishment of unfair behavior. Motivation and Emotion, 38, 578-588.

Shweder, R., Much, N., Mahapatra, M., \& Park, L. (1997). Divinity and the "big three" explanations of suffering. Morality and Health, 119, 119-169.

Skarlicki, D. P., \& Folger, R. (1997). Retaliation in the workplace: The roles of distributive, procedural, and interactional justice. Journal of Applied Psychology, 82, 434-443.

Skitka, L. J., Bauman, C. W., Aramovich, N. P., \& Morgan, G. S. (2006). Confrontational and preventative policy responses to terrorism: Anger wants a fight and fear wants "them" to go away. Basic and Applied Social Psychology, 28, 375-384.

Smith, J. M. (1974). The theory of games and the evolution of animal conflicts. Journal of Theoretical Biology, 47, 209-221.

Solomon, R. C. (1994). Sympathy and vengeance: The role of the emotions in justice. In S. H. M. van Goozen, N. E. Van de Poll, \& J. A. Sergeant (Eds.), Emotions: Essays on emotion theory (pp. 291-311). Hillsdale, NJ: Lawrence Erlbaum.

Spearman, C. (1904). "General Intelligence," objectively determined and measured. The American Journal of Psychology, 15, 201-292.

Stanovich, K. E. (2013). Why humans are (sometimes) less rational than other animals: Cognitive complexity and the axioms of rational choice. Thinking $\&$ Reasoning, 19, 1-26.

Stemmler, G. (2010). Somatovisceral activation during anger. In M. Potegal, G. Stemmler, \& C. Spielberger (Eds.), International handbook of anger (pp. 103-121). New York, NY: Springer.

Tellegen, A., Watson, D., \& Clark, L. A. (1999). On the dimensional and hierarchical structure of affect. Psychological Science, 10, 297-303.

Tiedens, L. Z., \& Linton, S. (2001). Judgment under emotional certainty and uncertainty: The effects of specific emotions on information processing. Journal of Personality and Social Psychology, 81, 973-988.

Tooby, J., \& Cosmides, L. (1992). The psychological foundations of culture. In J. H. Barkow, L. Cosmides, \& J. Tooby (Eds.), The adapted mind: Evolutionary psychology and the generation of culture (pp. 19-136). New York: Oxford University Press.

Tripp, T. M., Bies, R. J., \& Aquino, K. (2007). A vigilante model of justice: Revenge, reconciliation, forgiveness, and avoidance. Social Justice Research, 20, 10-34. 
Van den Bos, K., \& Lind, E. A. (2002). Uncertainty management by means of fairness judgments. In M. P. Zanna (Ed.), Advances in experimental social psychology, Vol. 34. (pp. 1-60). Academic Press.

Van den Bos, K., \& Miedema, J. (2000). Toward understanding why fairness matters: The influence of mortality salience on reactions to procedural fairness. Journal of Personality and Social Psychology, 79, 355-366.

Van den Bos, K., Poortvliet, P. M., Maas, M., Miedema, J., \& Van den Ham, E. J. (2005). An enquiry concerning the principles of cultural norms and values: The impact of uncertainty and mortality salience on reactions to violations and bolstering of cultural worldviews. Journal of Experimental Social Psychology, 41, 91-113.

Van Kleef, G. (2017). The social effects of emotions are functionally equivalent across expressive modalities. Psychological Inquiry, 28, 211-216.

Västfjäll, D., Slovic, P., Burns, W. J., Erlandsson, A., Koppel, L., Asutay, E., \& Tinghög, G. (2016). The arithmetic of emotion: Integration of incidental and integral affect in judgments and decisions. Frontiers in Psychology, 7, 325.

Wason, P. C., \& Johnson-Laird, P. N. (1972). Psychology of reasoning: Structure and content. Vol. 86. Harvard University Press.

Watson, D., \& Clark, L. A. (1992). Affects separable and inseparable: On the hierarchical arrangement of the negative affects. Journal of Personality and Social Psychology, 62, 489-505.

Watson, D., \& Clark, L. A. (1994). The PANAS-X: Manual for the positive and negative affect schedule-expanded form. Ames: The University of Iowa.

Watson, D., Clark, L. A., \& Tellegen, A. (1988). Development and validation of brief measures of positive and negative affect: the PANAS scales. Journal of Personality and Social Psychology, 54, 1063-1070.

Watson, D., \& Tellegen, A. (1985). Toward a consensual structure of mood. Psychological Bulletin, 98, 219-235.

Wilson, T. D., \& Gilbert, D. T. (2003). Affective forecasting. In M. P. Zanna (Ed.), Vol. 35. Advances in experimental social psychology (pp. 345-411). San Diego: Academic Press.

Wilson, T. D., \& Schooler, J. W. (2008). Thinking too much: Introspection can reduce the quality of preferences and decisions. In R. H. Fazio \& R. E. Petty (Eds.), Attitudes: Their structure, function, and consequences (pp. 299-317). New York: Psychology Press.

Wilson, T. D., Wheatley, T., Meyers, J. M., Gilbert, D. T., \& Axsom, D. (2000). Focalism: A source of durability bias in affective forecasting. Journal of Personality and Social Psychology, 78(5), 821 .

Wilson-Mendenhall, C. D., Barrett, L. F., Simmons, W. K., \& Barsalou, L. W. (2011). Grounding emotion in situated conceptualization. Neuropsychologia, 49, 1105-1127.

Winkielman, P., Zajonc, R. B., \& Schwarz, N. (1997). Subliminal affective priming resists attributional interventions. Cognition E Emotion, 11, 433-465.

Wisneski, D. C., \& Skitka, L. J. (2017). Moralization through moral shock: Exploring emotional antecedents to moral conviction. Personality and Social Psychology Bulletin, 43(2), 139-150.

Witvliet, C., Hinze, S. R., \& Worthington, E. L., Jr. (2008). Unresolved injustice: Christian religious commitment, forgiveness, revenge, and cardiovascular responding. Journal of Psychology and Christianity, 27, 110-119.

\section{Further reading}

Burke, B. L., Martens, A., \& Faucher, E. H. (2010). Two decades of terror management theory: A meta-analysis of mortality salience research. Personality and Social Psychology Review, 14, 155-195. 
Greenberg, J., Solomon, S., \& Pyszczynski, T. (1997). Terror management theory of selfesteem and cultural worldviews: Empirical assessments and conceptual refinements. In M. Zanna (Ed.), Advances in experimental social psychology, Vol. 29. (pp. 61-139). Academic Press.

Jost, J. T., Glaser, J., Kruglanski, A. W., \& Sulloway, F. J. (2003). Political conservatism as motivated social cognition. Psychological Bulletin, 129, 339-375.

Keltner, D., \& Gross, J. J. (1999). Functional accounts of emotions. Cognition \& Emotion, 13, 467-480.

Newport, F., \& Dugan, A. (2017). Partisan differences growing on a number of issues. August $3^{\text {rd }}$ Retrieved from https://news.gallup.com/opinion/polling-matters/215210/partisandifferences-growing-number-issues.aspx.

Saad, L. (2007). Democratic party winning on issues. December 7. Retrieved from http://news. gallup.com/poll/103102/democratic-party-winning-issues.aspx.

Winkielman, P., \& Berridge, K. C. (2004). Unconscious emotion. Current Directions in Psychological Science, 13, 120-123.

Zajonc, R. B. (1980). Feeling and thinking: Preferences need no inferences. American Psychologist, 35, 151-175. 
